\title{
BNST GluN2D-Containing NMDA Receptors Influence Anxiety- and Depressive-like Behaviors and Modulate Cell-Specific Excitatory/Inhibitory Synaptic Balance
}

\author{
Gregory J. Salimando, ${ }^{1,2,3,4}$ Minsuk Hyun, ${ }^{5}$ Kristen M. Boyt, ${ }^{6}$ and Danny G. Winder ${ }^{1,2,3,4,7,8}$ \\ ${ }^{1}$ Department of Molecular Physics \& Biophysics, Vanderbilt University School of Medicine, Nashville, Tennessee, 37212, ${ }^{2}$ Vanderbilt Brain Institute, \\ Vanderbilt University, Nashville, Tennessee, 37212, ${ }^{3}$ Vanderbilt University Medical Center, Vanderbilt Kennedy Center, Nashville, Tennessee, \\ 37203, ${ }^{4}$ Vanderbilt Center for Addiction Research, Vanderbilt University School of Medicine, Nashville, Tennessee, 37232, ${ }^{5}$ Howard Hughes \\ Medical Institute, Department of Neurobiology, Harvard Medical School, Boston, Massachusetts, $02115,{ }^{6}$ Bowles Center for Alcohol Studies, \\ Department of Pharmacology, University of North Carolina School of Medicine, Chapel Hill, North Carolina, 27599, ${ }^{7}$ Department of Pharmacology, \\ Vanderbilt University School of Medicine, Nashville, Tennessee, 37212, and ${ }^{8}$ Department of Psychiatry \& Behavioral Sciences, Vanderbilt University \\ School of Medicine, Nashville, Tennessee, 37212
}

Excitatory signaling mediated by NMDARs has been shown to regulate mood disorders. However, current treatments targeting NMDAR subtypes have shown limited success in treating patients, highlighting a need for alternative therapeutic targets. Here, we identify a role for GluN2D-containing NMDARs in modulating emotional behaviors and neural activity in the bed nucleus of the stria terminalis (BNST). Using a GluN2D KO mouse line $\left(\mathrm{GluN}_{2} \mathrm{D}^{-1-}\right)$, we assessed behavioral phenotypes across tasks modeling emotional behavior. We then used a combination of ex vivo electrophysiology and in vivo fiber photometry to assess changes in BNST plasticity, cell-specific physiology, and cellular activity profiles. GluN2D ${ }^{-/-}$male mice exhibit evidence of exacerbated negative emotional behavior, and a deficit in BNST synaptic potentiation. We also found that GluN2D is functionally expressed on corticotropin-releasing factor (CRF)-positive BNST cells implicated in driving negative emotional states, and recordings in mice of both sexes revealed increased excitatory and reduced inhibitory drive onto GluN2D $^{-/-}$BNST-CRF cells ex vivo and increased activity in vivo. Using a GluN2D conditional KO line (GluN2D ${ }^{\text {flx/flx }}$ ) to selectively delete the subunit from the BNST, we find that BNST-GluN2 ${ }^{\mathrm{fl} / \mathrm{flx}}$ male mice exhibit increased depressive-like behaviors, as well as altered NMDAR function and increased excitatory drive onto BNST-CRF neurons. Together, this study supports a role for GluN2D-NMDARs in regulating emotional behavior through their influence on excitatory signaling in a region-specific manner, and suggests that these NMDARs may serve as a novel target for selectively modulating glutamate signaling in stress-responsive structures and cell populations.

Key words: BNST; CRF; extended amydala; GluN2D; mood disorders; NMDAR

Significance Statement

Excitatory signaling mediated through NMDARs plays an important role in shaping emotional behavior; however, the receptor subtypes/brain regions through which this occurs are poorly understood. Here, we demonstrate that loss of GluN2D-containing NMDARs produces an increase in anxiety- and depressive-like behaviors in mice, deficits in BNST synaptic potentiation, and increased activity in BNST-CRF neurons known to drive negative emotional behavior. Further, we determine that deleting GluN2D in the BNST leads to increased depressive-like behaviors and increased excitatory drive onto BNST-CRF cells. Collectively, these results demonstrate a role for GluN2D-NMDARs in regulating the activity of stress-responsive structures and neuronal populations in the adult brain, suggesting them as a potential target for treating negative emotional states in mood-related disorders.

Received Feb. 4, 2020; accepted Feb. 26, 2020.

Author contributions: G.J.S. and D.G.W. designed research; G.J.S. and K.M.B. performed research; G.J.S. and K.M.B. analyzed data; G.J.S. wrote the first draft of the paper; G.J.S. and D.G.W. edited the paper; G.J.S. and D.G.W. wrote the paper; M.H. contributed unpublished reagents/analytic tools.
The authors declare no competing financial interests.

This work was supported by National Institutes of Health Grant T32 MH064913 to G.J.S., Grant R37 AA019455 to D.G.W., and a National Alliance for Research on Schizophrenia and Depression Distinguished Investigator Award to D.G.W. The contents of this manuscript are solely the responsibility of the authors and do not necessarily reflect the official views of the National Institutes of Health. We thank the National Institutes of Health INIA Stress Core U24AA025475 for CRF-FLP ISHs. Imaging and image data analysis 


\section{Introduction}

Dysregulated excitatory signaling is proposed to underlie a number of mood-related disorders (Graybeal et al., 2012; Sanacora et al., 2012). Despite this, the molecular underpinnings of how excitatory signaling influences emotional behavior are poorly understood, underscoring a critical need for continued study of the receptor and cell types involved in shaping the physiological changes that drive them. The NMDARs in particular have emerged as targets both associated with the pathobiology of these disease states and for developing treatments for their more intractable forms (Sanacora et al., 2008; Javitt et al., 2011; Ghasemi et al., 2014).

NMDARs are heteromeric receptors composed of two GluN1 subunits and a combination of two GluN2 or GluN3 subunits, with GluN2 subunits being more prominent in the adult brain (Hansen et al., 2018). GluN2 subunits are comprised of four isoforms (GluN2A-D), each conferring distinct physiological properties (Paoletti et al., 2013). NMDARs containing the GluN2D subunit (GluN2D-NMDARs) represent an interesting potential target due to their unique biophysical attributes, including prolonged deactivation kinetics, weakened $\mathrm{Mg}^{2+}$ sensitivity, and enhanced glutamate sensitivity (Vicini et al., 1998; Qian et al., 2005). Recent rodent studies have also reported that genetic deletion of GluN2D-NMDARs can alter emotional behavior; however, opposing phenotypes have been observed, warranting further investigation (Miyamoto et al., 2002; Yamamoto et al., 2017; Shelkar et al., 2019).

While GluN2D-NMDARs may represent an interesting therapeutic target due to their distinctive properties and lower expression in the adult brain (Monyer et al., 1994; Wenzel et al., 1996), little is known about their functional role in regions known to drive emotional behavior. The general restriction of GluN2D expression that occurs during development (Sheng et al., 1994; Cull-Candy et al., 2001) suggests that their influence might be significant in extended amygdalar regions. The bed nucleus of the stria terminalis (BNST) is one such region that has been heavily implicated in modulating emotional states, serving as a key integrator of negative valence and stress-related stimuli (Dong et al., 2001; Lebow and Chen, 2016). Excitatory signaling in the BNST has also been implicated in driving emotional behavior, with previous studies reporting that disruptions of inter- and intra-BNST excitatory synaptic function can lead to increases or decreases in anxiety- and depressive-like behaviors (Jennings et al., 2013; Kim et al., 2013; Glangetas et al., 2017). Moreover, the BNST is known to contain dense populations of neuropeptidergic cells that have been linked to regulating emotional behavior, in particular those expressing corticotropinreleasing factor (CRF, Crh). These cells (BNST-CRF) have been shown to drive negative valence, with numerous preclinical studies linking increases in both BNST and extended amgydalar CRF

were performed in part through the use of the Vanderbilt University School of Medicine Cell Imaging Shared Resource (supported by National Institutes of Health Grants CA68485, DK20593, DK58404, DK59637, and EY08126). Behavioral studies and analysis were performed in part through the use of the Vanderbilt Mouse Neurobehavior Laboratory. We thank Dr. Samuel Centanni for technical assistance in setting up the in vivo fiber photometry experiments and analyzing relevant data; Dr. Robert Matthews for assistance with confocal microscopy imaging for ISH studies; Drs. Fiona Harrison and John Allison for technical assistance and expertise on running and operating equipment for behavioral studies and relevant data analysis; Drs. Masahiko Watanabe and Bernado Sabatini for generously providing a GluN2D primary antibody for use in our IHC analyses and the Crh-IRES-Flp0 mice used in these studies, respectively; Elana Milano and Bridget Morris for laboratory support and technical assistance; and Rafael Perez for assistance with figure/diagram design.

Correspondence should be addressed to Danny G. Winder at danny.winder@vanderbilt.edu.

https://doi.org/10.1523/JNEUROSCI.0270-20.2020

Copyright $\odot 2020$ the authors cell signaling to depression- and stress-related states/disorders (Lebow et al., 2012; Sink et al., 2013; Pleil et al., 2015; Fetterly et al., 2019).

Using behavioral testing and electrophysiological recording techniques, we demonstrate here that mice constitutively lacking GluN2D (GluN2D ${ }^{-/-}$) exhibit increases in anxiety- and depressive-like behaviors, and associated disruptions in BNST synaptic potentiation. Closer examination of GluN2D expression across the BNST revealed the subunit to be present on BNST-CRF neurons, suggesting a role for GluN2D-NMDARs in regulating their activity. Ex vivo whole-cell electrophysiology and in vivo recordings of calcium transients from these neurons in GluN2D ${ }^{-1-}$ mice confirmed this, showing converging evidence of increased basal excitatory activity. To specifically explore the role of GluN2D-NMDAR signaling in the BNST, we used a conditional KO line (GluN2D ${ }^{\text {flx/flx }}$ ) to examine the effects of BNST-GluN2D loss in adult mice. Further, we used a Crh-promoter driven Flp line to study the cell type-specific effects of regionally restricted GluN2D deletion on BNST-CRF cell physiology. We find that BNST-GluN2D deletion produces increased depressive-like behavior, as well as increased excitatory drive onto the BNSTCRF neurons similar to what we observed in GluN2D ${ }^{-1-}$ mice. Overall, these studies suggest that GluN2D-NMDARs play an important role in shaping excitatory signaling in the BNST and specifically in BNST-CRF cells that may correlate with aspects of emotional behavior.

\section{Materials and Methods}

Animals

Male and female mice of at least 8 weeks of age were used throughout this study. GluN2D constitutive KO mice $\left(\mathrm{GluN}^{2} \mathrm{D}^{-/-}\right)$were purchased from the RIKEN Experimental Animal Division Repository (RBRC \#01840), whereas Crh-IRES-Cre, Ai14, and C57BL/6J mice were purchased from The Jackson Laboratory (stock \#012704, \#007908, and \#00064). CrfTomato mice were generated as previously reported (Chen et al., 2015; Silberman et al., 2013). GluN2D conditional KO mice (GluN2D ${ }^{\text {flx/flx }}$ ) were

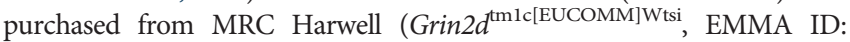
04857) and bred as outlined by the Wellcome Trust Sanger Institute guidelines for their suite of conditional ready mice. Crh-IRES-FlpO mice were generously provided for our use by the laboratory of Bernado Sabatini (The Jackson Laboratory, stock \#031559). To visualize CRF cells in brain slices from rodents lacking the GluN2D subunit, GluN2D ${ }^{-1-}$ mice were crossed with Crf-Tomato mice for constitutive deletion studies (GluN2D ${ }^{-/-} /$Crf-Tomato), and GluN2D ${ }^{\text {flx/flx }}$ mice were crossed with hemizygous Crh-IRES-FlpO mice (GluN2D $\mathrm{D}^{\mathrm{fl} / \mathrm{flx}} / \mathrm{Crf}-\mathrm{Flp}$ ) for regional GluN2D deletion studies. GluN2D ${ }^{-1-}$ mice were also bred to the Crh-IRES-Cre line to generate the mice necessary for conducting in vivo fiber photometry studies (GluN2D ${ }^{-/-} / \mathrm{Crf}-\mathrm{Cre}$ ). GluN2D ${ }^{-1-}$, Crf-Tomato, and CrhIRES-FlpO mice were genotyped using protocols reported for each respective line on The Jackson Laboratory's website, while custom primers were designed for endpoint PCR to genotype the GluN2D ${ }^{\text {flx/flx }}$ mice (forward primer: GTGTGACCAGGAAGCCACTT, reverse primer: TCCTTGA TCCCGTCCCTCAA)

For behavioral studies using the GluN2D ${ }^{-/-}$and GluN2D flx/flx mouse line, male mice were primarily used to replicate the conditions of previously published behavioral work with the GluN2D ${ }^{-/-}$line (Ikeda et al., 1995; Miyamoto et al., 2002; Obiang et al., 2012; Yamamoto et al., 2017; Shelkar et al., 2019). For ex vivo electrophysiological and in vivo fiber photometry studies using the GluN2D ${ }^{-/-} / \mathrm{Crf}_{-}$Tomato, GluN2D ${ }^{-/-}$/ Crf-Cre, and GluN2D $\mathrm{D}^{\text {flx/flx }} /$ Crf-Flp lines, mice of both sexes were used to minimize the total number of animals. No sex differences were observed in these studies; and as such, all data are compiled across groups into values representative of both sexes. All mouse lines were maintained on a C57BL/6J background and backcrossed as needed. Mice were group-housed with 2-5 individuals per cage and maintained on a $12 \mathrm{~h}$ light/dark cycle (lights on at $0600 \mathrm{~h}$ ) under controlled 
temperature $\left(20^{\circ} \mathrm{C}-25^{\circ} \mathrm{C}\right)$ and humidity $(30 \%-50 \%)$ levels. Mice were given access to food and water ad libitum. All treatments and interventions were approved by the Vanderbilt Animal Care and Use Committee.

\section{Behavioral testing}

All experiments took place during the light phase of the cycle. Grouphoused male GluN2D ${ }^{-1-}$, and male GluN2D $\mathrm{D}^{\mathrm{fl} / \mathrm{flx}}$, mice were transferred into the vivarium 3 weeks before testing and allowed a minimum of 1 week for acclimation. Following acclimation, mice were singly housed for 2 weeks; $5 \mathrm{~d}$ before the start of behavioral testing, mice were handled daily to help reduce experimenter-induced stress as previously described (Olsen and Winder, 2010). On test days, mice were brought into procedure rooms $\sim 1 \mathrm{~h}$ before the start of any experiment to allow for acclimatization, which was performed under full light ( $\sim 300-400$ lux $)$ in rooms while mice were provided food and water ad libitum. All equipment used during testing was cleaned with a $70 \%$ ethanol solution before start, and in between each animal run, to mask odors and other scents.

Open field test (OFT). Mice were run in ENV-S10S open field activity chambers (Med Associates) fitted with IR photograph-beam arrays for 60 min under full light in the chambers ( $\sim 200-300$ lux $)$. Total locomotor activity and zone analyses for total time spent in the designated center and surround zones of the activity arena were performed using Med Associates software.

Light/dark $(L / D)$ box. Mice were run using the same activity chambers described above, with inserts made of blacked out Plexiglas fitted into the left side of each chamber, occupying approximately half of the total chamber area. Mice were placed into the dark side to begin the test and run for $10 \mathrm{~min}$. Total movement between and activity within each side of the chamber was automatically recorded via Med Associates software based on IR beam breaks. Zone analyses for total time spent in each side of the chamber, as well as total zone entries and overall locomotion (distance traveled), were later performed using Med Associates software.

Elevated zero maze (EZM). Mice were run using a custom EZM apparatus measuring $34 \mathrm{~cm}$ inner diameter, $46 \mathrm{~cm}$ outer diameter, placed $40 \mathrm{~cm}$ off the ground on four braced legs, with two open quadrants and two closed quadrants. Testing was performed under illuminated conditions $(\sim 200-300$ lux for open quadrants and $\sim 100-150$ lux for closed quadrants), with mice initially placed into one of the open quadrants, after which they were run for $5 \mathrm{~min}$ in the maze and filmed continuously. Videos were analyzed automatically via ANY-maze software (Stoelting) for total time spent in the designated open quadrants compared with total time spent in the closed quadrants, and presented as percent total time in open quadrants overall. Total locomotion and quadrant entries were similarly assessed via ANY-maze.

Forced swim test (FST). The FST was always performed on the final day of all behavioral testing batteries. Mice were placed in Plexiglas cylinders containing room temperature $\left(\sim 22^{\circ} \mathrm{C}-23^{\circ} \mathrm{C}\right)$ tap water for $6 \mathrm{~min}$ while being continuously filmed. Videos were then analyzed to determine the total immobility time (i.e., lack of swimming/struggling while in water) observed in mice during the last $4 \mathrm{~min}$ of the test (first $2 \mathrm{~min}$ were designated as a habituation period to the water/test). All results were hand-scored by individuals blinded to the genotype of test mice.

Novelty-induced hypophagia (NIH). Testing was performed as previously described (Louderback et al., 2013). In brief, mice were subjected to $4 \mathrm{~d}$ of training on drinking a highly palatable food (liquid Ensure, vanilla flavor) in their home cages, and a final testing day in a novel cage. Training consisted of $30 \mathrm{~min}$ of access to Ensure in the home cage under low red lighting conditions ( $\sim 40-50$ lux $)$, and mice were timed for latency (seconds) to first lick of sipper bottles containing Ensure and then for total consumption of Ensure (grams) at the end of each session. On test day, mice were placed in a new cage devoid of bedding under bright lights ( 400-500 lux) immediately before Ensure access, after which latency to first lick and total consumption of Ensure at the end of the $30 \mathrm{~min}$ session were measured. Results were scored by individuals blinded to treatment groups, and total consumption of Ensure was measured across the entire experiment to rule out potential issues of a feeding phenotype.

\section{Slice preparation for electrophysiology}

Male and female mice were transported from animal colony housing facilities to the laboratory and placed in a sound-attenuated chamber for $1 \mathrm{~h}$ before ex vivo brain slice preparation as previously described (Harris et al., 2018; Centanni et al., 2019; Fetterly et al., 2019). Mice were anesthetized with isoflurane gas, after which brains were quickly removed and placed in ice-cold sucrose ACSF containing the following: $194 \mathrm{~mm}$ sucrose, $20 \mathrm{~mm} \mathrm{NaCl}, 4.4 \mathrm{~mm} \mathrm{KCl}, 2 \mathrm{~mm} \mathrm{CaCl}, 1 \mathrm{~mm} \mathrm{MgCl}_{2}, 1.2 \mathrm{~mm}$ $\mathrm{NaH}_{2} \mathrm{PO}_{4}, 10 \mathrm{~mm}$ glucose, and $26 \mathrm{~mm} \mathrm{NaHCO}$. For slices prepared for field potential recordings, $0.9 \mathrm{~mm}$ of ascorbic acid was added to help preserve cell health in the interface chamber. Dissecting solution was saturated with $95 \% \mathrm{O}_{2} / 5 \% \mathrm{CO}_{2}(\mathrm{v} / \mathrm{v})$. Coronal slices $300 \mu \mathrm{m}$ in thickness were prepared using a VT1200S vibratome (Leica Microsystems). Slices containing anterior portions of the dorsolateral BNST (dlBNST) (bregma, 0.26-0.02 $\mathrm{mm}$ ) were selected using the internal capsule, anterior commissure, and stria terminalis as landmarks.

Field potential recordings. After dissection, slices were transferred to an interface recording chamber (Fine Science Tools), where they were perfused with heated $\left(\sim 29^{\circ} \mathrm{C}\right)$ and oxygenated $\left(95 \% \mathrm{O}_{2} / 5 \% \mathrm{CO}_{2}\right.$, v/v) ACSF ( $124 \mathrm{~mm} \mathrm{NaCl}, 4.4 \mathrm{~mm} \mathrm{KCl}, 2 \mathrm{~mm} \mathrm{CaCl}{ }_{2}-2 \mathrm{H}_{2} \mathrm{O}, 1.2 \mathrm{~mm} \mathrm{MgSO}_{4}$, $1 \mathrm{~mm} \mathrm{NaH}_{2} \mathrm{PO}_{4}, 10 \mathrm{~mm}$ glucose, and $26 \mathrm{~mm} \mathrm{NaHCO}_{3}, \mathrm{pH}$ 7.2-7.4, 295$305 \mathrm{mOsm}$ ) at a rate of $\sim 2 \mathrm{ml} / \mathrm{min}$. Slices were allowed to equilibrate in ACSF for at least $1 \mathrm{~h}$ before recording began. A bipolar Ni-chrome wire stimulating electrode and a borosilicate glass recording electrode (1-2 $\mathrm{M} \Omega$ ) filled with ACSF were placed in the dIBNST to elicit and record extracellular field responses, which were amplified using an AxoClamp 2B amplifier (Molecular Devices). Baseline responses to electrical stimulus at an intensity that produced $\sim 40 \%$ of the maximum response were recorded for $20 \mathrm{~min}$ at a rate of $0.05 \mathrm{~Hz}$. After acquisition of a stable baseline, LTP was induced with two trains of $100 \mathrm{~Hz}, 1 \mathrm{~s}$ tetanus delivered with a $20 \mathrm{~s}$ intertrain interval at the same intensity as the baseline stimuli. The N1 (an index of sodium channel-dependent firing) was also monitored, and experiments in which it changed by more than $\sim 20 \%$ were discarded. Analyses were made from the percent change of the N2 (an index of the extracellular population response) from baseline 0-10 min after tetanus and 51-60 min after tetanus. Electrical signals were low-pass filtered at $2 \mathrm{kHz}$, digitized at $20 \mathrm{kHz}$, and acquired with a Digidata 1322A and pClamp 9.2 system (Molecular Devices). All relevant analysis work was conducted with Clampex 10.6 software (Molecular Devices).

Whole-cell recordings. Following dissection, slices were transferred to a holding chamber containing heated $\left(\sim 29^{\circ} \mathrm{C}\right)$ and oxygenated $(95 \%$ $\mathrm{O}_{2} / 5 \% \mathrm{CO}_{2}, \mathrm{v} / \mathrm{v}$ ) ACSF. Slices were allowed to equilibrate in ACSF for at least $1 \mathrm{~h}$, after which they were transferred onto a submerged recording chamber on a BX51WI upright microscope (Olympus). In the chamber, slices were continuously perfused with oxygenated and heated ACSF at a rate of $2 \mathrm{ml} / \mathrm{min}$. Recording electrodes (3-6 M $\Omega$ ) were pulled on a Flaming/Brown Micropipette Puller (Stutter Instruments) using thinwalled borosilicate glass capillaries, and filled with a cesium gluconate internal solution (117 mM Cs-gluconate, $20 \mathrm{~mm}$ HEPES, 0.4 mm EGTA, 5 mM TEA-Cl, $2 \mathrm{~mm} \mathrm{MgCl}_{2}, 4 \mathrm{~mm}$ ATP, and $0.3 \mathrm{~mm}$ GTP, pH 7.2-7.4, 285-290 mOsm). A bipolar Ni-chrome stimulating electrode was placed in the stria terminalis $\sim 100-300 \mu \mathrm{m}$ dorsal to the recorded cell, and electrical responses were evoked via local fiber stimulation $(5-15 \mathrm{~V}$ at a duration of 100-150 $\mu$ s) at $0.1 \mathrm{~Hz}$. After achieving whole-cell configuration, cells were allowed to dialyze and equilibrate for 2-5 min before recording. Postsynaptic parameters were continuously monitored during all experiments, and cells were excluded from final analysis if the access resistance changed by $>20 \%$ in either direction. For sEPSC measurements made in voltage-clamp mode, responses were isolated by adding $25 \mu \mathrm{M}$ picrotoxin $\left(\mathrm{GABA}_{\mathrm{A}}\right.$ receptor antagonist, Tocris Bioscience) into the ACSF and bath-applying over slices while recording at a holding potential of $-70 \mathrm{mV}$. sIPSC measurements were performed by adding $10 \mu \mathrm{M}$ NBQX (pan-AMPA and kainate receptor antagonist, Tocris Bioscience) and $25 \mu \mathrm{m}$ AP-V (pan-NMDAR antagonist, Tocris Bioscience) into bath-applied ACSF, while maintaining a holding potential of $-70 \mathrm{mV}$. mEPSC recordings were also made at a holding potential of $-70 \mathrm{mV}$, while ACSF containing $1 \mu \mathrm{m}$ of TTX (sodium channel blocker, Abcam) and $25 \mu \mathrm{M}$ picrotoxin was perfused over the slice. In paired-pulse ratio 
(PPR) experiments, paired-evoked $100-200 \mathrm{pA}$ responses at $0.05 \mathrm{~Hz}$ were elicited, and interstimulus intervals (ISIs) of 30,50, and $100 \mathrm{~ms}$ were used. For measuring the evoked, isolated NMDAR EPSCs used for analyzing differences in NMDAR kinetics, the holding potential for the cells was adjusted to $40 \mathrm{mV}$, and ACSF containing $10 \mu \mathrm{M}$ NBQX and $25 \mu \mathrm{M}$ picrotoxin was perfused over the slice. Evoked, isolated NMDAR EPSCs were also elicited for GluN2C/D antagonist wash-on experiments, but this time using a modified, $0 \mathrm{Mg}^{2+}$-based ACSF (124 $\mathrm{mm} \mathrm{NaCl}, 4 \mathrm{~mm} \mathrm{KCl}, 1 \mathrm{~mm} \mathrm{NaH}{ }_{2} \mathrm{PO}_{4}$, and $3.7 \mathrm{~mm} \mathrm{CaCl}_{2}-2 \mathrm{H}_{2} \mathrm{O}, \mathrm{pH}$ 7.4-7.2, 295-305 mOsm) containing $25 \mu \mathrm{m}$ picrotoxin, $10 \mu \mathrm{M}$ NBQX, and $40 \mu \mathrm{M}$ of the selective GluN2C/2D antagonist DQP-1105 (selective GluN2C/D antagonist, Tocris Bioscience) and using a $-70 \mathrm{mV}$ holding potential. Slices were prepared as described above for these experiments but allowed to recover and equilibrate in heated, normal ACSF before being transferred to the rig and perfused with the modified 0 $\mathrm{Mg}^{2+}$ ACSF. Signals were acquired with a Multiclamp 700B amplifier (Molecular Devices), digitized via a Digidata 1322A, and analyzed with pClamp 10.6 software (Molecular Devices). Spontaneous and miniature voltage-clamp recordings were analyzed via Clampfit 10.6 (Molecular Devices) by measuring the peak amplitudes and frequencies of events over a $6 \mathrm{~min}$ period (in three, $2 \mathrm{~min}$ bins). PPRs were analyzed by dividing the value of the amplitude of the second response over the amplitude of the first (P2/P1), and the resulting ratios plotted out for each ISI period. Evoked NMDAR EPSCs decay kinetics were interrogated by examining the amplitude of the current trace at half of the tau $(\tau)$ value. Evoked NMDAR EPSCs isolated in $0 \mathrm{Mg}^{2+}$ ACSF for DQP-1105 washon studies were analyzed by measuring the percent change in the amplitude of the response from baseline during the last $8 \mathrm{~min}$ of the recording (i.e., following DQP application and drug wash-out).

\section{RNAscope ISH}

RNAscope studies were performed as previously described (GhamariLangroudi et al., 2015). Three mRNA species expressed by neurons in the dlBNST were visualized across separate sets of experiments using the enhanced fluorescent ISH technique RNAscope (Advanced Cell Diagnostics). RNAscope cDNA probes and detection kits were purchased from Advanced Cell Diagnostics and used according to the company's online protocol for fresh-frozen tissue. The probe sets directed against $\mathrm{Crh}$ and Grin2d were designed from sequence information from the mouse RefSeq mRNA IDs NM_205769.2 and NM_008172.2, respectively, and custom probes for the Flp recombinase were designed by Advanced Cell Diagnostics (catalog \#448191).

C57BL/6J and Crh-IRES-FlpO male mice, aged 8-10 weeks, were anesthetized using isoflurane, and the brains were quickly removed and frozen in Tissue Tek OCT compound (Sakura) using Super Friendly Freeze-It Spray (Thermo Fisher Scientific). Brains were stored at $-80^{\circ} \mathrm{C}$ until cut on a CM3000 cryostat (Leica Microsystems) to produce $16 \mu \mathrm{m}$ coronal sections. Sections were adhered to warm, charged glass microscope slides, and immediately refrozen before being stored at $-80^{\circ} \mathrm{C}$ until ready to undergo the RNAscope procedure. In brief, following the Advanced Cell Diagnostics protocol for fresh frozen tissue, slides were fixed for $15 \mathrm{~min}$ in ice-cold 4\% PFA and then dehydrated in a sequence of ethanol serial dilutions (50\%, 70\%, and $100 \%$, twice each). Slides were briefly air-dried, and then a hydrophobic barrier was drawn around the tissue sections using a Pap Pen (Vector Labs). Slides were then incubated with Advanced Cell Diagnostics' Pretreat Four solution for $30 \mathrm{~min}$ at room temperature in a humidified chamber. Following protease treatment, sections were incubated with RNAscope cDNA probes $(2 \mathrm{~h})$, and then with a series of signal amplification reagents provided by the Multiplex Fluorescence Kit from Advanced Cell Diagnostics: Amp 1-FL (30 min), Amp 2-FL (15 min), Amp 3-FL (30 $\mathrm{min}$ ), and Amp 4-FL ALT A (15 min); 2 min of washing in RNAscope wash buffer $(1 \times$ from $50 \times$ stock) was performed between each step, and all incubation steps with the cDNA probes and amplification reagents were performed using a HybEZ oven (Advanced Cell Diagnostics) at $40^{\circ}$ C. cDNA probe mixtures were prepared at a dilution of 50:1 of the $\mathrm{C} 1$ channel probe (Grin2d) and C2 channel probe (Crh) for C57 studies, and at 50:1 of $\mathrm{C} 1$ probe for Crh and C2 probe for Flp for studies in the Crh-IRES-FlpO line. Sections were also stained for DAPI using the reagent provided by the Fluorescent Multiplex Kit. Immediately following DAPI staining, sections were mounted and coverslipped using Aqua-Poly Mount media (PolySciences) and left to dry overnight in a dark, cool place. Sections from the dlBNST were collected in pairs, using one section for incubation with the cDNA probes and another for incubation with a probe for bacterial mRNA (dapB, Advanced Cell Diagnostics) to serve as a negative control. Sections were imaged using a 710 scanning confocal microscope (Carl Zeiss) at $20 \times(20 \times / 0.50$ N.A. lens) and $63 \times$ magnification $(63 \times / 0.50$ N.A. oil immersion lens), and composite images of the dlBNST were generated as TIF files and analyzed in Fiji/ImageJ. Images from sections treated with the negative control probe for each pair of slides were used to determine brightness and contrast parameters that minimized observation of bacterial transcripts and autofluorescence, and these adjustments were then applied to the images from experimental sections treated with the cDNA probes. Adjusted experimental images were then analyzed in a designated region of interest around the dIBNST. Cells in these ROIs were identified using both DAPI-stained nuclei and the borders present between cells identified with the help of grayscale differential interference contrast overlays, and the total number of cells in each region were counted. Cells were appraised for the presence of Grin2d and Crh signal to determine the total number of cells showing probe expression either alone or in combination in C57 studies, and similarly for the presence of $\mathrm{Crh}$ and Flp signal in Crh-IRESFlpO studies. Transcripts were readily identified as round, fraction delimited spots over and surrounding DAPI-labeled nuclei.

\section{Stereotaxic surgery procedures}

Adult mice ( $\sim 8$ weeks of age) were anesthetized with isoflurane (initial dose $=3 \%$, maintenance dose $=1.5 \%$ ), and surgery was performed using an Angle Two stereotaxic frame (Leica Microsystems) to intracranially inject adeno-associated virus (AAV) into the dlBNST based on the Paxinos and Franklin (2004) mouse brain atlas (from bregma: AP 0.14, $\mathrm{ML} \pm 0.88, \mathrm{DV}-4.24,15.03^{\circ}$ tilt) at a rate of $100 \mathrm{nl} / \mathrm{min}$. For behavior studies using the GluN2D flx/flx line, male mice were bilaterally injected with $\sim 300 \mathrm{nl}$ of recombinant AAV5-CMV-eGFP or AAV5-CMV-CreeGFP (UNC Vector Core), and given a 4 week recovery period. GluN2D $\mathrm{D}^{\mathrm{fl} / \mathrm{flx}} / \mathrm{Crf}$-Flp mice of either sex used for physiology studies were bilaterally injected with $\sim 300 \mathrm{nl}$ of a 1:1 mixture of an AAV9-Ef1afDIO-tdTomato virus (Stanford Vector Core) and the AAV5-CMV-CreeGFP virus, and similarly given 4 weeks recovery before producing slices for ex vivo recordings.

For photometry studies, GluN2D ${ }^{-1-} /$ Crf-Cre mice of either sex were injected with $\sim 300 \mathrm{nl}$ of AAV9-Syn-FLEX-jGCaMP7f-WPRE (Addgene) into the right dlBNST, and then given a 3 week recovery period to allow for full expression of the virus. Following this period, mice underwent a second round of surgery to place a fiberoptic cable implant (4.1 mm fiber, Doric Lenses) just above the injection site of the virus within the dlBNST $(\sim 0.1 \mathrm{~mm}$ above DV coordinate listed above). After placing the fiberoptic into position, a system consisting of a light-curable Optibond primer and adhesive agent (Henry Schein Medical) and Herculite XRV dental composite enamel (Kerr) was applied to the mouse's skull to firmly affix and hold the fiberoptic in position. Briefly, after exposure of the skull, gel etchant was used to clean the skull, a screw was placed rostral to the craniotomy hole, and the implant was slowly lowered through the previously made craniotomy hole. Optibond FL Primer was applied around the implant, followed by Optibond FL light-curable adhesive, and last the light-curable Herculite enamel. Mice were given a minimum 1 week recovery period following implant surgery to allow for the surgery sites to fully heal before the start of in vivo calcium signal recording.

\section{In vivo fiber photometry recordings}

Optical recordings of GCaMP7f fluorescence were acquired using a RZ5P fiber photometry detection system (Tucker-Davis Technologies), consisting of a processor with Synapse software (Tucker-Davis Technologies), and optical components (Doric Lenses and ThorLabs). Excitation wavelengths generated by LEDs $(470 \mathrm{~nm}$ blue light and $405 \mathrm{~nm}$ violet light) were relayed through a filtered fluorescence minicube at spectral bandwidths of $460-495$ and $405 \mathrm{~nm}$ to a prebleached mono fiberoptic cable connected to the implant on top of each animal's 
head. Power output for the primary $470 \mathrm{~nm}$ channel at the tip of the fiberoptic cable was measured at $\sim 25-30 \mu \mathrm{W}$. Single emissions were detected using a femtowatt photoreceiver with a lensed fiber cable adapter. Signal in both 470 and $405 \mathrm{~nm}$ channels were monitored continuously throughout all recordings, with the $405 \mathrm{~nm}$ signal used as an isobestic control for both ambient fluorescence and motion artifacts introduced by movement of the fiberoptic implant. Wavelengths were modulated at frequencies of $210-220$ and $330 \mathrm{~Hz}$, respectively, and power output maintained at $20 \mathrm{~mA}$ with a DC offset of $3 \mathrm{~mA}$ for both light sources. All signals were acquired at $1 \mathrm{kHz}$ and lowpass filtered at $3 \mathrm{~Hz}$. Mice were housed and handled as described above, with the addition of a $5 \mathrm{~min}$ session each handling day during which the mice were hooked up to the fiberoptic cable to allow them to become accustomed the tethered cable. Mice were transported to the procedure room and habituated for $1 \mathrm{~h}$. Mice were then connected to the photometry system, and following a 1-2 min period to adjust to these manipulations, a 30 min recording session was conducted to observe basal activity in the dlBNST. Mice were placed in a custom arena and allowed to explore for the duration of the recording. Following testing, all mice were perfused and tissue was assessed for both proper targeting of both initial viral injections and optic fiber placement via immunohistochemistry.

Analysis of the GCaMP signal was done with a custom-written MATLAB code (can be provided on request), with the bulk fluorescent signal from both the 470 and 405 channels normalized to compare differences in calcium-mediated event frequencies across groups using the 405 as a control channel. Linear regression was used to correct for the bleaching of signal for the duration of each recording, using the slope of the $405 \mathrm{~nm}$ signal fitted against the $470 \mathrm{~nm}$ signal. Detection of GCaMPmediated fluorescence is presented as a change in the $470 \mathrm{~nm} / \mathrm{fitted}$ $405 \mathrm{~nm}$ signal over the fitted 405 signal $(\Delta \mathrm{F} / \mathrm{F})$. Peak analysis of calciummediated events to determine frequency across subjects was performed by running the normalized, filtered signals produced by our MATLAB code through Clampfit 10.6 software and performing a template matching event detection analysis on each file. The template was set to match the average width and amplitude of an imputed, positive-going calciummediated event, with a template matching variable set at $\sim 2.5$.

\section{Immunohistochemistry}

Immunostaining for the GluN2D protein in neural tissue sections was performed using a modification of the protocol previously described (Yamasaki et al., 2014). In brief, mice were anesthetized using isoflurane and underwent transcardial perfusion using ice-cold PBS and a 4\% PFA solution made in PBS. Following perfusion, brains were quickly removed and placed in ice-cold 4\% PFA overnight for postfixation, and then into an ice-cold 30\% sucrose solution prepared in PBS for 2-3 d to cryoprotect the tissue. Brains were then embedded in paraffin wax and sectioned at $5 \mu \mathrm{m}$ on a microtome. Sections containing the dlBNST were baked in a hybridization oven at $50^{\circ} \mathrm{C}$ for $1-2 \mathrm{~h}$ to melt wax, before going through a series of washes in Citrisol solution, $100 \%, 95 \%, 70 \%$, and 50\% ethanol, PBS and $1 \%$ hydrogen peroxide. Sections were next digested in a pepsin solution (Dako, $1 \mathrm{mg} / \mathrm{ml}$ ) at $39^{\circ} \mathrm{C}$ for $\sim 20 \mathrm{~min}$, and then washed with PBS and a PBS/Triton-X100 (PBS-T, 0.1\%) solution. A hydrophobic barrier was drawn using a PAP-Pen. Sections were then blocked with a buffer containing 10\% normal donkey serum (Jackson ImmunoResearch Laboratories) in PBS for $1 \mathrm{~h}$ at room temperature in a humidified chamber. Primary antibody for GluN2D (generously provided by the laboratory of Masahiko Watanabe) was applied at a concentration of $1 \mathrm{mg} / \mathrm{ml}$ in a solution of $10 \%$ normal donkey serum and PBS-T, and the sections were stored in a humidified chamber at $4^{\circ} \mathrm{C}$ for $\sim 72-96 \mathrm{~h}$. Primary antibody was removed with a series of four washes in ice-cold PBS-T buffer before a biotin conjugated secondary antibody (Jackson ImmunoResearch Laboratories) prepared in $10 \%$ normal donkey serum and PBS-T was applied at a concentration of 1:2000 for $\sim 3 \mathrm{~h}$ at room temperature in a humidified chamber. Secondary antibody was removed with four washes in ice-cold PBS-T, and then the tissue underwent amplification for the GluN2D signal using a Cy3-Tyramide Signal Amplification kit (PerkinElmer). In brief, HRP reagent provided by the kit was applied to sections at a concentration of 1:100 in room temperature. TNB buffer overnight at $4^{\circ} \mathrm{C}$ in a humidified chamber, and washed off the following day via three, $5 \mathrm{~min}$ washes using TNT buffer. Cy3 fluorophore was then prepared at a 1:50 dilution and applied to the sections for $5 \mathrm{~min}$ at room temperature before being washed off with three, 5 min washes in TNT buffer. Last, sections were treated with a DAPI stain $(1: 10,000)$ for $\sim 30 \mathrm{~s}$ at room temperature before being mounted and coverslipped using warm, Aqua-Poly Mount media. Once dried, sections were then imaged using the same confocal microscope described above.

For imaging Cre, eGFP, tdTomato, and GCaMP7f expression introduced via viral injections into the dlBNST, animal tissue was prepared and removed following PFA perfusion as described above and sections made at $40 \mu \mathrm{m}$. Floating tissue sections were then incubated with mouse anti-Cre (1:1000, MAB3120, Millipore) and chicken anti-GFP (1:1000, ab13970, Abcam) primary antibodies prepared in a solution of $10 \%$ normal donkey serum and PBS-T for $\sim 72 \mathrm{~h}$ at $4^{\circ} \mathrm{C}$ as necessary. Cy3 donkey anti-mouse (1:400, Jackson ImmunoResearch Laboratories) or Cy2 donkey anti-chicken (1:400) secondary Abs prepared in PBS-T were applied next for $24 \mathrm{~h}$ at $4^{\circ} \mathrm{C}$, after which sections were counterstained with DAPI $(1: 10,000)$ and then mounted and coverslipped. Slides were imaged using an Imager M2 upright fluorescent microscope (Carl Zeiss) at $5 \times$ and $10 \times$ magnification. Endogenous eGFP signal was used to validate the expression of GCaMP7f in the dlBNST, and DAPI staining combined with differential interference contrast imaging was used to validate the position of implanted fiberoptic cables for mice used in photometry studies.

\section{Western blotting}

Bilateral tissue punches $(\sim 0.8 \mathrm{~mm})$ of the dlBNST collected from GluN2D ${ }^{-1-}$ or GluN2D ${ }^{+/+}$mice, and later from GluN2D flx/flx mice injected with either a virus encoding Cre or eGFP, were homogenized in lysis buffer containing $2 \%$ SDS and $1 \times$ protease inhibitor cocktail (Roche Diagnostics) via pipetting and passage through a 27 gauge syringe and an insulin syringe. Samples were centrifugated at $1000 \times g$ for $10 \mathrm{~min}$, and total protein concentration was then determined using a BCA protein assay kit (Thermo Fisher Scientific). Whole homogenate was used for analysis, and all samples were diluted to an equal concentration by mixing with sample buffer containing $62.5 \mathrm{~mm}$ Tris- $\mathrm{HCl}, \mathrm{pH}$ 6.8 , glycerol, $5 \%$ SDS, $0.5 \%$ bromophenol blue, and $5 \% \beta$-mercaptoethanol. Diluted samples were boiled at $90^{\circ} \mathrm{C}$ for $3 \mathrm{~min}$, and then $10-20 \mu \mathrm{g}$ of each was run on a $7 \%$ polyacrylamide-resolving gel. Protein was then transferred onto a single nitrocellulose membrane, and then stained for total protein using Ponceau S. Membranes were cut at specific molecular weights and probed with different antibodies for select products. Primary antibodies used included mouse anti-NMDAR 2D (1:5000, MAB5578, Millipore), mouse anti- $\beta-3$ tubulin (1:1000, 4466S, Cell Signaling Technology), and mouse anti-GAPDH (1:10,000, MAB374, Millipore). All primary antibody dilutions were prepared in $5 \%$ powdered milk solution in $1 \times$ TBS/Triton-X100 (TBS-T), and applied to blots overnight at $4^{\circ} \mathrm{C}$. Blots were washed 4 times in $1 \times$ TBS-T the following day, and then probed with an anti-mouse, HRP-conjugated secondary antibody (1:8000, W402B, Promega) in 5\% milk, $1 \times$ TBS-T for $\sim 2 \mathrm{~h}$ at room temperature. Blots were then washed an additional four times with fresh $1 \times$ TBS-T and then soaked in Western Lighting PlusECL solution (PerkinElmer) for 1-2 min before imaging on X-ray film. Blots were appraised as needed for changes in total protein expression via densitometry analysis using Fiji/ImageJ software.

\section{Experimental design and statistical analysis}

The number of animals used in each experiment were predetermined based on analyses of similar experiments in the literature and supplemented as needed based on observed effect sizes (Louderback et al., 2013; Silberman et al., 2013; Ghamari-Langroudi et al., 2015; Holleran et al., 2016; Centanni et al., 2019; Fetterly et al., 2019). All data are presented as mean \pm SEM for each group, and all statistical analyses were performed using Prism 8 software (GraphPad Software). We used both male and female mice within this study. When sex was not found to be a statistically significant factor, we combined male and female data for analysis. For behavior experiments, data comparing metrics between KO and WT groups across tasks were analyzed using unpaired, two-tailed Student's $t$ tests, whereas analyses of changes in locomotive behavior 

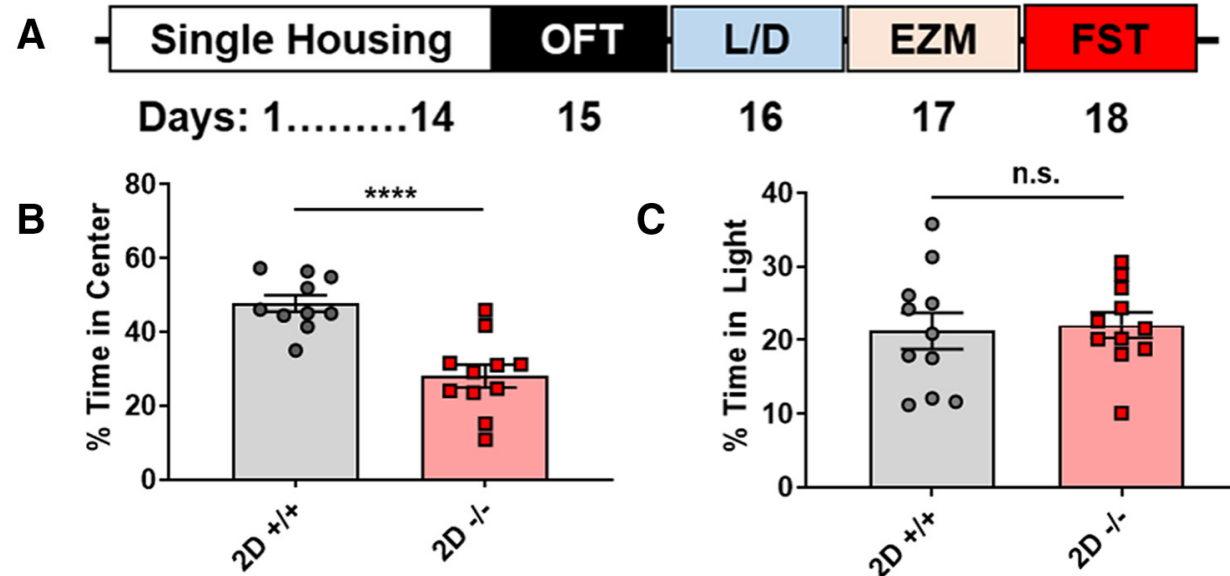

D

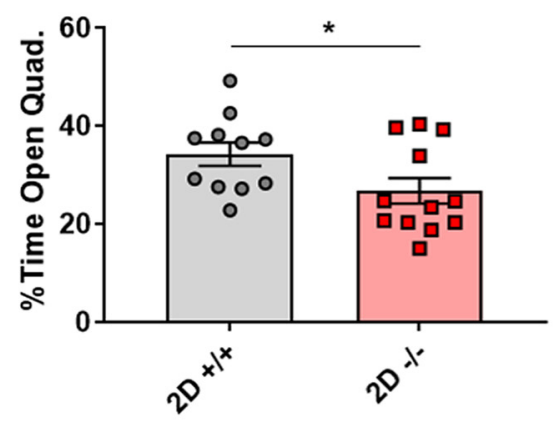

E
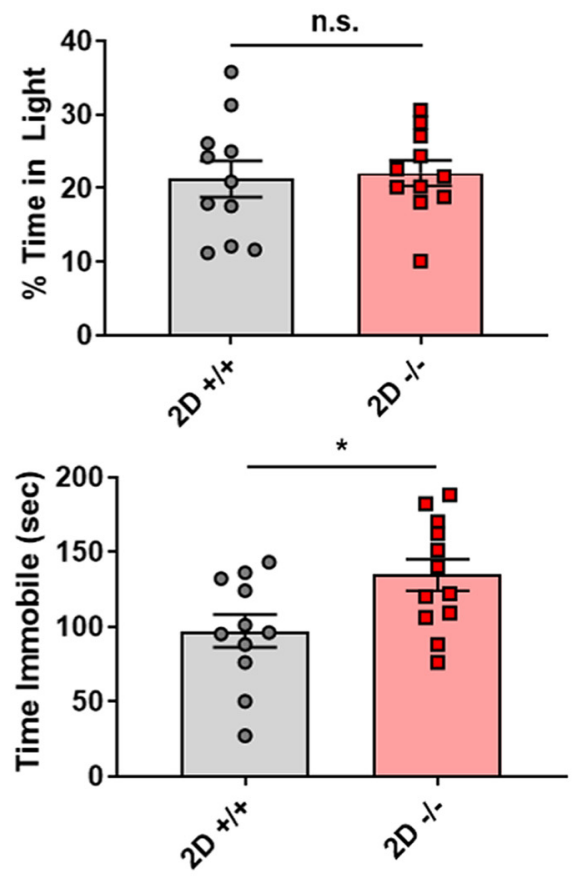

$\mathbf{F}$

OFT - Locomotor Activity
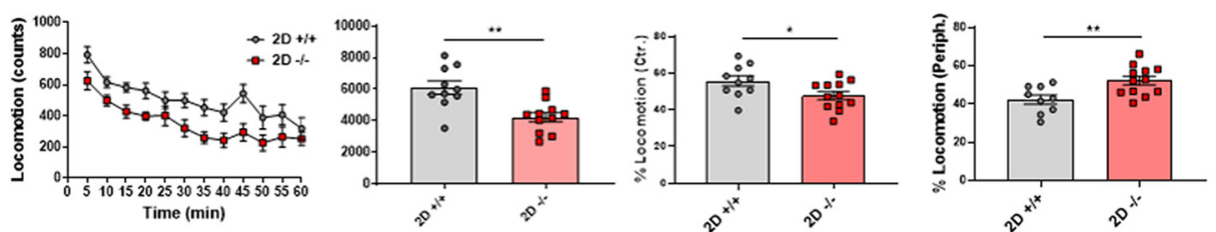

G

L/D - Locomotor Activity
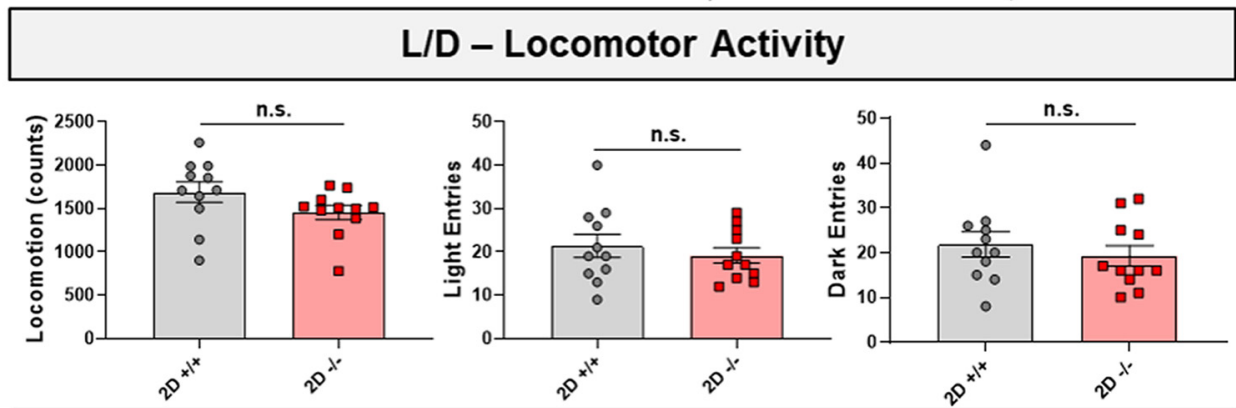

H

EZM - Locomotor Activity
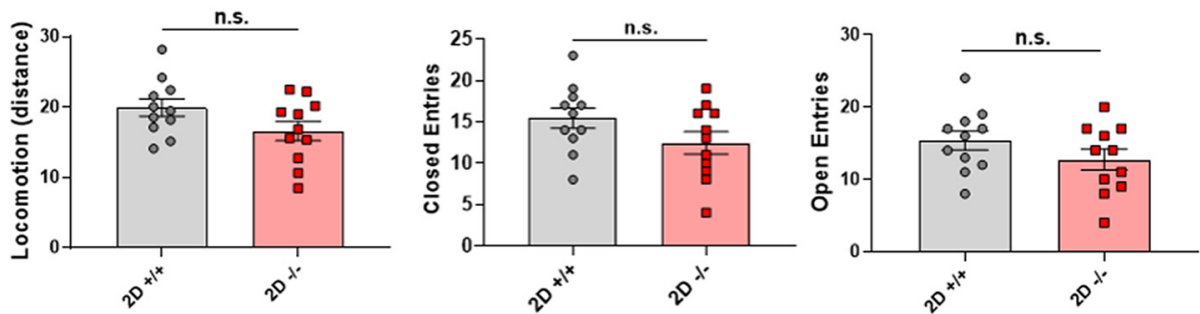

Figure 1. GluN2D KO mice exhibit altered affective phenotypes. $A$, Design schema and timeline for the $4 \mathrm{~d}$ behavioral testing battery, consisting of OFT, L/D, EZM, and FST. B, Percent total time spent in the center zone of the OFT arena was shown to be significantly decreased in GluN2D KO $\left(2 D^{-1-}\right)$ mice compared with GluN2D WT $\left(2 D^{+/+}\right)$littermates $(p<0.001)$. C, No difference in the percent total time spent on the light side of the $\mathrm{L} / \mathrm{D}$ box was found between $2 \mathrm{D}^{-/-}$and $2 \mathrm{D}^{+/+}$mice $(p=0.793)$. $\boldsymbol{D}$, Percent total time spent in the open quadrants of the EZM was, however, found to be significantly decreased in the $2 D^{-l-}(p=0.048)$. $E$, Total time spent immobile during the course of the FST was also found to be significantly increased for the 
between both groups across multiple time points were performed using two-way ANOVAs along with Sidak's multiple comparison post hoc test, and corrected $p$ values are reported in the text as needed. Two-tailed $t$ test analyses were also performed on LTP data from KO and WT mice, total cell counts, and CRF(+) for ISH studies, drug effects of DQP on NMDAR eEPSC amplitude and decay kinetics, sEPSC, sIPCS and mEPSC amplitude and frequency values in ex vivo recordings, and frequency values for imputed calcium-mediated events in in vivo recordings (all of which consisted of comparisons between only two groups). For PPR data examining changes in the ratio across three separate ISIs, a two-way ANOVA was used, along with Sidak's multiple comparison post hoc test, to assess effects of genotype and the PPR over time, with corrected $p$ values presented in the text. For all analyses, significance levels were set at $\alpha=0.05$. Detailed statistics are provided within the text and figure legends.

\section{Results}

\section{GluN2D KO mice exhibit enhanced negative emotional phenotypes}

Previous behavioral studies in GluN2D KO (GluN2D $\left.{ }^{-1-}\right)$ mice have reported opposing phenotypes, with an initial study suggesting a decrease in anxiety- and depressive-like behaviors, while subsequent studies found these behaviors to be significantly increased in the GluN2D ${ }^{-1-}$ (Miyamoto et al., 2002; Yamamoto et al., 2017; Shelkar et al., 2019). In order to address these conflicting findings, we used a battery of four tests to assess different aspects of negative emotional behavior between GluN2D $^{-1-}$ and GluN2D ${ }^{+/+}$(wildtype) littermates (Fig. $1 A$ ). Age-matched male mice ( $\sim 12$ weeks) underwent OFT, L/D, EZM, and FST testing over 4 consecutive days. GluN2D ${ }^{-/-}$mice displayed a significant decrease in the percent total center time in the OFT compared with GluN2D ${ }^{+/+}$controls (Fig. $1 B ; 2 \mathrm{D}^{+/+}$ $=47.8 \pm 2.3 \%$ time in center, $2 \mathrm{D}^{-1-}: 28.1 \pm 3.1 \%$ time in center, $t_{(19)}=5.05, p<0.0001$, unpaired $t$ test). Additionally, percent total time in the open quadrants of the EZM was also significantly decreased in the GluN2D ${ }^{-1-}$ mice compared with controls (Fig. $1 D ; 2 \mathrm{D}^{+/+}$: $34.2 \pm 2.4 \%$ time open quadrant, $2 \mathrm{D}^{-/-}$: $26.8 \pm 2.6 \%$ time open quadrant, $t_{(21)}=2.10, p=0.048$, unpaired $t$ test). Differences in behavior were not observed between groups in the $\mathrm{L} / \mathrm{D}$ (Fig. $1 C ; 2 \mathrm{D}^{+/+}: 21.3 \pm 2.5 \%$ time in light, $2 \mathrm{D}^{-l-}$ : $22.1 \pm 1.7 \%$ time in light, $t_{(20)}=0.27, p=0.793$, unpaired $t$ test). Total immobility time on the FST was significantly increased in the GluN2D ${ }^{-/-}$compared with GluN2D ${ }^{+/+}$mice (Fig. 1E; $2 \mathrm{D}^{+/+}: 97.1 \pm 11.0 \mathrm{~s}$ immobile, $2 \mathrm{D}^{-/-}: 134.5 \pm 10.6 \mathrm{~s}$ immobile, $t_{(21)}=2.45, p=0.023$, unpaired $t$ test). Collectively, our findings from the OFT, EZM, and FST suggest an overt increase in anxiety- and depressive-like behaviors in the GluN2D ${ }^{-1-}$ mice, generally consistent with the results presented in Yamamoto et al. (2017) and Shelkar et al. (2019).

$\leftarrow$

$2 \mathrm{D}^{-/-}$compared with the $2 \mathrm{D}^{+/+}(p=0.023) . \boldsymbol{F}$, Analysis of total locomotion during the OFT via a plot of minute-to-minute time course for activity (counts, i.e., IR beam breaks) during the $60 \mathrm{~min}$ recording (left) and summary graph of total locomotion throughout (right). $2 D^{-1-}$ shows a significant decrease in total locomotion on in the OFT $(p=0.002)$, as well as a significant decrease in percent distance traveled in the center, and an increase in percent distance traveled in the periphery of the arena $(p=0.033$ and $p=0.008$, respectively). The $2 D^{-1-}$ also shows no overt deficits in locomotor activity in the $(G) L / D$ or the $(\boldsymbol{H})$ EZM. Analysis of distance traveled and total entries into the light and dark sides of the chamber in the $\mathrm{L} / \mathrm{D}$ is not significantly different between genotypes $(p=0.117, p=0.503$, and $p=$ 0.490 , respectively), and similar measures of total distance traveled and entries into the open or closed quadrants in the EZM ( $p=0.089, p=0.192$, and $p=0.117$, respectively) also revealed no indication of a locomotor phenotype. Data are mean $\pm S E M$, overlain with individual points $\left(\mathrm{N}_{2 \mathrm{D}}{ }^{-/-}=11, \mathrm{~N}_{2 \mathrm{D}+1+}=12\right) .{ }^{*} p \leq 0.05,{ }^{* *} p \leq 0.01,{ }^{* * *} p \leq 0.0001$. n.s., not significant.
While no apparent anxiety-like behavior was observed in the $\mathrm{L} / \mathrm{D}$, it is possible that differences in our experimental design for the task (black inset, one-half area of activity chamber as opposed to one-third area) (Crawley and Goodwin, 1980) could have increased the possibility of false negatives.

As an important control, we also assessed changes in total locomotion across all relevant tasks. Total locomotion was found to be decreased in GluN2D ${ }^{-1-}$ mice compared with GluN2D ${ }^{+/+}$ controls in the OFT, consistent with previous findings (Ikeda et al., 1995; Obiang et al., 2012; Shelkar et al., 2019). However, further analysis of changes in percent total distance traveled in the center and periphery of the chamber between both groups showed more modest differences in locomotion (Fig. $1 F$; total locomotion: $2 \mathrm{D}^{+/+}: 6093 \pm 420.2$ beam breaks, $2 \mathrm{D}^{-l-}: 4219 \pm 295.4$ beam breaks, $t_{(19)}=3.70, p=0.002$; \% distance center: $2 \mathrm{D}^{+/+}: 55.8 \pm$ $2.8 \%, 2 \mathrm{D}^{-1-}: 47.7 \pm 2.2 \%, t_{(20)}=2.29, p=0.033 ; \%$ distance periphery: $2 \mathrm{D}^{+/+}: 42.4 \pm 2.4 \%, 2 \mathrm{D}^{-/-}: 53.3 \pm 2.2 \%, t_{(19)}=2.99$, $p=0.008$, unpaired $t$ tests). Additionally, measurements of differences in locomotor activity and zone/quadrant entries compared between the two groups in the LD and EZM tasks revealed no difference in overall locomotion (Fig. $1 G, H$; LD total locomotion: $2 \mathrm{D}^{+/+}: 1690 \pm 117.9$ beam breaks, $2 \mathrm{D}^{-/-}$: $1455 \pm 82.0$ beam breaks, $t_{(20)}=1.64, p=0.117$; light entries: $2 \mathrm{D}^{+/+}: \sim 21 \pm 3$, $2 \mathrm{D}^{-/-}: \sim 19 \pm 2, t_{(20)}=0.68, p=0.503$; dark entries: $2 \mathrm{D}^{+/+}$: $\sim 22 \pm 3,2 \mathrm{D}^{-1-}: \sim 19 \pm 2 t_{(20)}=0.70, p=0.490$; EZM total locomotion: $2 \mathrm{D}^{+/+}$: $19.9 \pm 1.2 \mathrm{~m}$ traveled, $2 \mathrm{D}^{-/-}$: $16.6 \pm 1.4 \mathrm{~m}$ traveled, $t_{(20)}=1.79, p=0.089$; open quadrant entries: $2 \mathrm{D}^{+/+}$: $\sim 15 \pm 1,2 \mathrm{D}^{-1-}: \sim 13 \pm 1, t_{(20)}=1.35, p=0.192$; closed quadrant entries: $2 \mathrm{D}^{+/+}: \sim 15 \pm 1,2 \mathrm{D}^{-1-}: \sim 12 \pm 1, t_{(20)}=1.64, p=0.117$, unpaired $t$ tests). Our observations here are thus in close agreement with those of previously published datasets that suggest that the effects of constitutive GluN2D deletion are more in line with altered emotional behavior and not gross locomotor function.

\section{GluN2D deletion produces deficits in BNST excitatory synaptic potentiation}

While GluN2D-NMDARs have been shown to regulate synaptic function in the cerebellum, basal ganglia, and hippocampus (Harney et al., 2008; Zhang et al., 2014; Swanger et al., 2015; von Engelhardt et al., 2015; Dubois et al., 2016), their role in extended amygdalar circuits regulating emotional behaviors has been unexplored. Deletion or pharmacological blockade of select NMDAR subtypes in the BNST can produce both alterations in synaptic function and negative emotional behavior (Wills et al., 2012; Louderback et al., 2013), and previous studies suggested the potential presence of GluN2D in this region (Watanabe et al., 1992, 1993; Wenzel et al., 1996; Yamasaki et al., 2014). To confirm this, we collected tissue punches from the dlBNST of GluN2D $\mathrm{D}^{+/+}$and GluN2D ${ }^{-1-}$ mice to test for the presence of GluN2D protein. Western blot analysis of whole tissue lysates revealed a band for GluN2D in dlBNST lysates, as well as in lysates taken from regions known to express high levels of the subunit, such as the thalamus and hypothalamus. These bands were absent from all regions in samples collected from GluN2D ${ }^{-1-}$ mice (Fig. 2A). Additional means of validation were also performed via immunohistochemistry and yielded similar results for GluN2D expression and absence in the BNST across GluN2D $^{+/+}$and GluN2D ${ }^{-1-}$ tissue samples, as well as thalamus sample as an additional control (Fig. 2B).

We next set out to examine whether GluN2D-NMDARs contribute to shaping synaptic function in the BNST by performing extracellular field potential recordings in the dlBNST to assess differences in NMDAR-dependent LTP of evoked field potentials 
in acute ex vivo brain slices from GluN2D $^{+/+}$and GluN2D ${ }^{-1-}$ mice. After establishing a stable baseline recording, we applied two brief trains of tetanizing electrical stimulation to induce LTP (Fig. 2C, inset, arrow) and observed a robust potentiation of the evoked responses in GluN2D $\mathrm{D}^{+/+}$slices comparable to previously reported findings by our laboratory (Wills et al., 2012). In the GluN2D $^{-1-}$ slices, we observed a marked decrease in the amplitude of responses immediately following tetanus compared with GluN2D ${ }^{+/+}$controls, an effect that was maintained for up to $10 \mathrm{~min}$ (Fig. $2 C, D$; \% increase over baseline $2 \mathrm{D}^{+/+}: 173.6 \pm 9.0 \%$, $2 \mathrm{D}^{-1-}: 133.3 \pm 5.0 \%, t_{(17)}=3.52, p=0.003$, unpaired $t$ test). While there was a clear reduction in the early phase of the response to tetanus in GluN2D ${ }^{-1-}$ slices, LTP at later time points in the dIBNST was not altered, as a comparison of the overall amplitude of the field potential during the final $10 \mathrm{~min}$ of a $60 \mathrm{~min}$ post-tetanus recording revealed no significant difference between GluN2D $^{-1-}$ or GluN2D ${ }^{+/+}$responses (Fig. $2 D$; \% increase over baseline $2 \mathrm{D}^{+/+}: 139.3 \pm$ $6.8 \%, 2 \mathrm{D}^{-1-}: 123.5 \pm 5.3 \%, t_{(17)}=1.72, p=$ 0.105 , unpaired $t$ test). Overall, these data suggest that GluN2D-NMDARs may contribute to the induction of short-term synaptic potentiation (STP) in the dlBNST, consistent with pharmacological studies of hippocampal STP (Volianskis et al., 2013, 2015).

\section{Grin $2 d$ mRNA colocalizes with CRF transcripts in dlBNST}

Given the alteration in field potential-level synaptic plasticity that we observed in the BNST of GluN2D ${ }^{-1-}$ mice, we next performed whole-cell patch-clamp recording experiments to assess whether genetic deletion of GluN2D altered basal synaptic function. However, when using unbiased selection and patching only visually identified cells throughout the dlBNST, we observed no significant differences in the physiological profiles of cells recorded from in GluN2D ${ }^{+/+}$ and GluN2D ${ }^{-1-}$ brain slices when analyzing sEPSC current events (Fig. $3 A$; frequency: $2 \mathrm{D}^{+/+}: 1.5 \pm 0.3 \mathrm{~Hz}, 2 \mathrm{D}^{-/-}: 1.4 \pm 0.2 \mathrm{~Hz}$, $t_{(34)}=0.02, p=0.982$; amplitude: $2 \mathrm{D}^{+/+}$: $-24.5 \pm 0.9 \mathrm{pA}, 2 \mathrm{D}^{-/-}:-25.6 \pm 0.9 \mathrm{pA}, t_{(34)}$ $=0.88, p=0.383$, unpaired $t$ tests) or the kinetics of isolated NMDAR-mediated evoked postsynaptic currents (eEPSCs, Fig. $3 B ; 2 \mathrm{D}^{+/+}$: $72.2 \pm 10.5$ half tau [ms], $2 \mathrm{D}^{-1-}: 67.9 \pm 9.5$ half tau $[\mathrm{ms}], t_{(17)}=0.30, p=0.767$, unpaired $t$ test).

The BNST contains a number of highly heterogeneous and specialized cell populations (Kash et al., 2015; Lebow and Chen, 2016), such that the lack of observable differences in synaptic function in individual neurons could be due to a restricted pattern of expression of GluN2D within these subpopulations. To
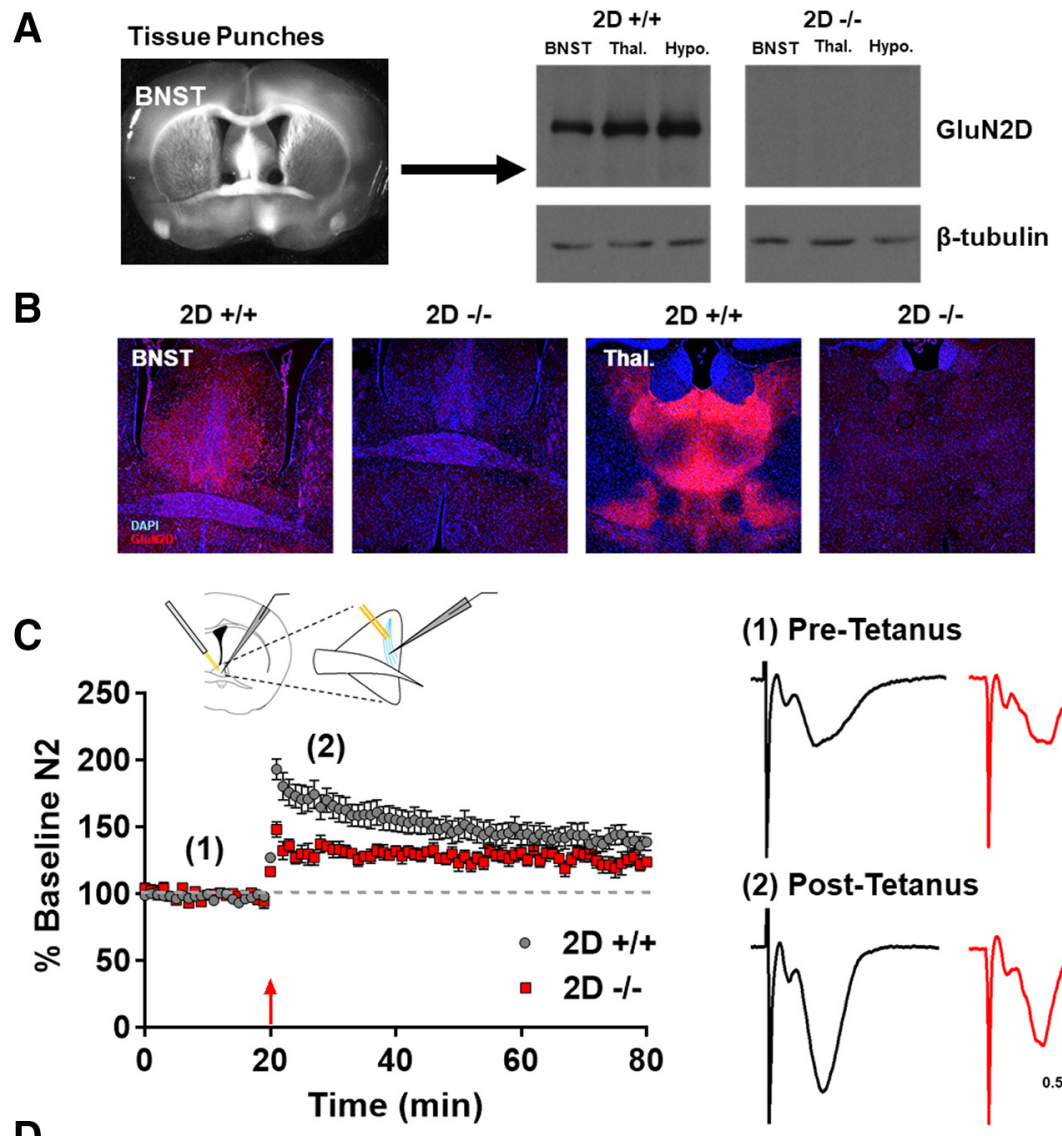

(1) Pre-Tetanus

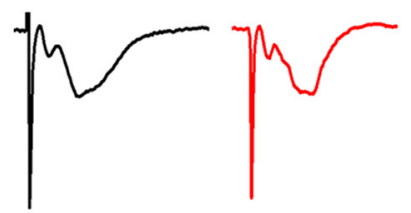

(2) Post-Tetanus

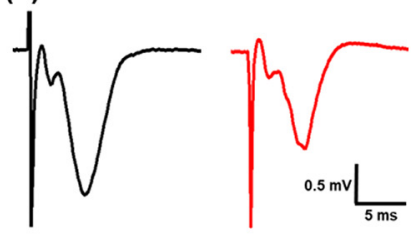

1-10 min. Post-Tetanus

51-60 min. Post-Tetanus
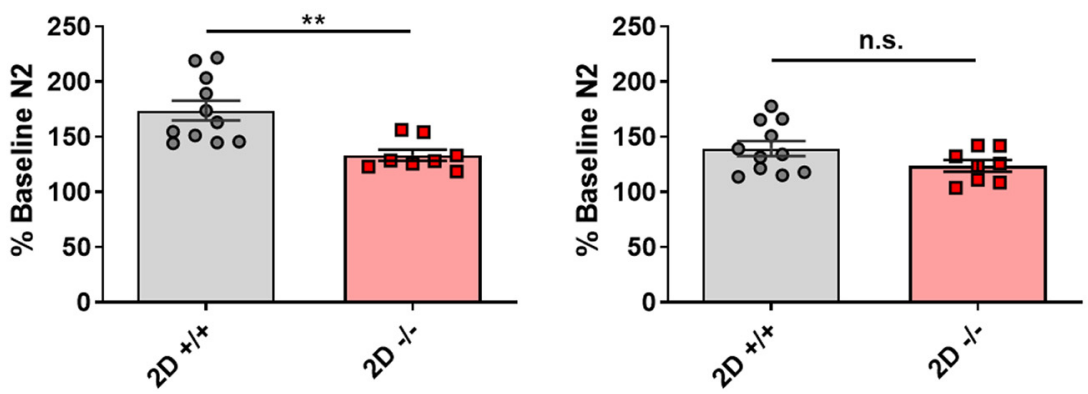

Figure 2. GluN2D deletion produces deficits in BNST excitatory synaptic potentiation. $A$, Western blot analysis of total protein lysate taken from tissue punches $(0.8 \mathrm{~mm})$ of the dIBNST, medial thalamus (thal.), and hypothalamus (hypo.) from GluN2D WT $\left(2 D^{+/+}\right)$and GluN2D KO $\left(2 D^{-l-}\right)$ mice. Left, Representative image of punch locations for the dIBNST. Right, Representative blot of bands for both GluN2D protein and control $\beta 3$-tubulin. $B$, Representative $5 \times$ images of the BNST and the medial thalamus taken from $2 \mathrm{D}^{+/+}$and $2 \mathrm{D}^{-/-}$, stained for the GluN2D protein (red) and counterstained with the nuclear marker DAPI (blue). C, Averaged time courses of excitatory postsynaptic field potentials recorded from the dIBNST of $2 \mathrm{D}^{+/+}$and $2 \mathrm{D}^{-/-}$acute, ex vivo brain slices after high-frequency stimulation (arrow; two $1 \mathrm{~s}$ trains at $100 \mathrm{~Hz}$ ). Right, Representative traces from both $2 \mathrm{D}^{+/+}$(black) and $2 \mathrm{D}^{-/-}$(red) slices before tetanus (1) and $\sim 10$ min after tetanus (2). A schematic of the recording setup is shown as an inset above the time course plot. $D$, Summary graphs of the averaged field potential responses 0-10 min after tetanus (left) and 51-60 min after tetanus (right). A significant difference in the amplitude of responses recorded from $2 D^{-1-}$ slices was noted for up to 10 min following tetanus compared with $2 D^{+/+}$controls $(p=$ $0.003)$, but not during the final 10 min of recording $(p=0.105)$. Data presented across summary graphs as mean \pm SEM with individual points overlain $\left(\mathrm{n}_{2 \mathrm{D}^{+/+}}=11\right.$ slices from $\mathrm{N}_{2 \mathrm{D}^{+/+}}=9$ mice, $\mathrm{n}_{2 \mathrm{D}^{-/-}}=8$ slices, from $\mathrm{N}_{2 \mathrm{D}^{-/-}}=7$ mice). ${ }^{* *} p \leq 0.01$. n.S., not significant.

determine the expression profile of GluN2D in dlBNST we used an enhanced form of fluorescent ISH (RNAscope) to examine the expression of GluN2D transcripts throughout the region and on select cell populations. We focused in particular on those cells expressing the stress-related peptide CRF, as this population has been previously implicated in the regulation of emotional 


\section{A}

\section{Spontaneous EPSC Recordings}
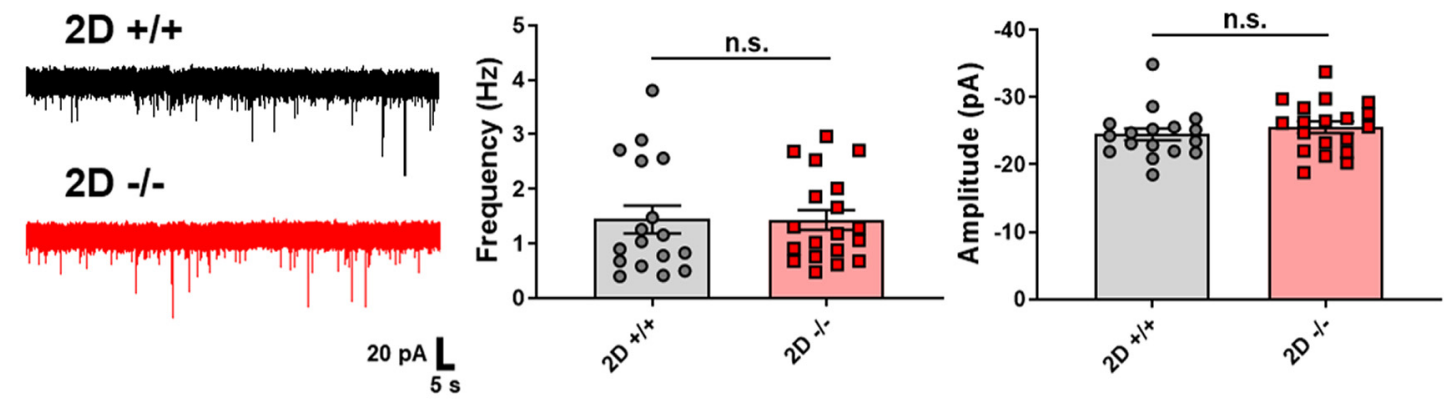

B

Isolated NMDAR EPSC
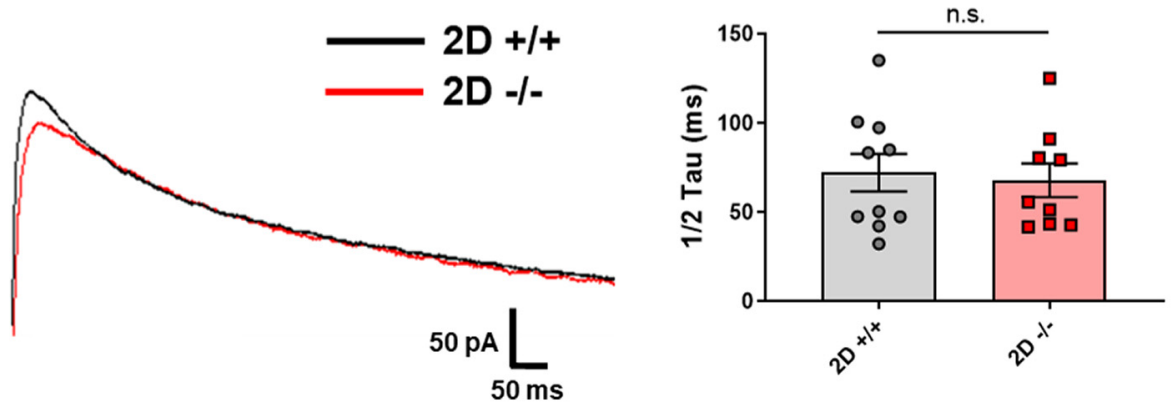

Figure 3. Unbiased examination of dIBNST neurons in the GluN2D ${ }^{-1-}$ does not identify overt differences in basal excitatory physiology. $A$, Representative traces of $s E P S C$ recordings from

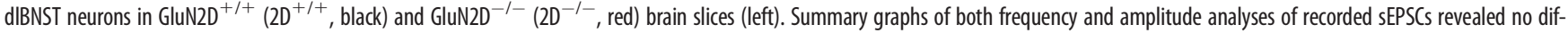
ferences in either metric across groups when sampling cells with an unbiased approach (frequency: $p=0.981$, amplitude: $p=0.383 ; \mathrm{n}_{2 D^{+/+}}=17$ cells from $\mathrm{N}_{2 D^{+/+}}=4$ mice, $\mathrm{n}_{2 D^{-/-}}=19$ cells from $\mathrm{N}_{2 \mathrm{D}^{--}-}=7$ mice). $\boldsymbol{B}$, Representative traces of electrically isolated NMDAR-EPSCs (holding potential: $40 \mathrm{mV}$ ) from $2 \mathrm{D}^{+/+}$and $2 \mathrm{D}^{-1-}$ dIBNST neurons (left). Summary graph to the right shows analysis of changes in the decay kinetics (milliseconds) of NMDAR-isolated currents from both groups revealed no difference when using an unbiased approach to identify and patch dIBNST neurons ( $p=0.767 ; \mathrm{n}_{2 D^{+/+}}=10$ cells from $\mathrm{N}_{2 D^{+/+}}=5$ mice, $\mathrm{n}_{2 D^{-/-}}=9$ cells from $\mathrm{N}_{2 D^{-/-}}=5$ mice). Data are mean \pm SEM with individual data points overlain. n.S., not significant.

behaviors (Sink et al., 2013; Silberman and Winder, 2013; Pleil et al., 2015; Marcinkiewcz et al., 2016; Fetterly et al., 2019). Using custom cDNA probes designed for Grin2d (GluN2D) and Crh (CRF) transcripts, we examined transcript expression patterns and colocalization across the left and right dlBNST of three separate adult male C57BL/6J mice (Fig. 4A). Consistent with our hypothesis, we found $2 \mathrm{D}$ transcripts to be diffusely expressed throughout the dlBNST and present on a minority of BNST cells when comparing the number of Grin2d transcript-positive cells with total unlabeled cells across both the right and left dlBNST (Fig. $4 B$; Grin2d[-] $=1661.7$ cells, $\sim 67.5 \%$ of total cells, Grin2d $[+]=$ 773.3 cells, $\sim 32.5 \%$ of total cells; lower insert: $t_{(4)}=7.17, p=0.002$, unpaired $t$ test). Upon closer inspection of the stratification of the Crh-labeled population, we observed that signal for this transcript was highly colocalized on cells labeled with probes for the Grin2d transcript (Fig. $4 \mathrm{C}$; $\mathrm{Crh}[+]$ only $=19$ cells, $\sim 22.8 \%$ of total $\mathrm{Crh}[+]$ cells, Crh + Grin $2 d[+]=61$ cells, $\sim 77.2 \%$ of total $\mathrm{Crh}[+]$ cells; lower insert: $t_{(4)}=5.11, p=0.007$, unpaired $t$ test), suggesting the potential of increased expression of GluN2D-NMDARs on this subset of BNST neurons.

Functional synaptic GluN2D-containing NMDARs are expressed on adult mouse BNST-CRF neurons

Given the concentration of Grin2d transcript on Crh transcript positive neurons, we next sought to assess whether functional GluN2D-NMDARs were present on these cells (BNST-CRF), and how the loss of this subunit altered their synaptic physiology.
To identify BNST-CRF cells in ex vivo brain slices for whole-cell patch-clamp electrophysiology, we crossed the GluN2 $\mathrm{D}^{-/-}$mice to a previously validated CRF reporter line (Crf-Tomato) (Silberman et al., 2013; Chen et al., 2015) (Fig. 5A). We then isolated electrically evoked synaptic NMDAR-mediated EPSCs at BNST-CRF neurons via the use of a modified, $\mathrm{Mg}^{2+}$-free artificial cerebrospinal fluid (Wills et al., 2012) while holding the cells at $-70 \mathrm{mV}$; after which, the GluN2C/2D selective antagonist DQP-1105 (Acker et al., 2011) was bath applied $(40 \mu \mathrm{M})$ (Fig. $5 B, C$; baseline: $8 \mathrm{~min}, \mathrm{DQP}$ wash-on: $10 \mathrm{~min}$, wash-out: $10 \mathrm{~min}$ ). In slices from GluN2D ${ }^{+/+}$mice, DQP-1105 wash-on produced a $\sim 36 \%$ decrease in the amplitude of the evoked NMDAR EPSC, an effect that was absent in slices prepared from GluN2D ${ }^{-1-}$ mice (Fig. $5 C$; CRF $2 \mathrm{D}^{+/+}$pre-DQP: $103.1 \pm 2.0 \%$ baseline, post-DQP: $\sim 67.9 \pm 8.2 \%$ baseline, $t_{(8)}=4.21, p=0.003$, unpaired $t$ test; CRF $2 \mathrm{D}^{-1-}$ pre-DQP: $100.0 \%$ baseline, post-DQP: $\sim 100.0 \pm$ $7.3 \%$ baseline, $t_{(6)}=0.003, p=0.997$, unpaired $t$ test). In in vitro systems, GluN2D-NMDARs have been shown to exhibit substantially slower kinetics relative to NMDARs containing the GluN2A/B or C subunits (Vicini et al., 1998; Paoletti et al., 2013; Hansen et al., 2018). Consistent with these previously reported differences, we noted that the decay kinetics of electrically isolated NMDAR EPSCs (40 mV holding potential) on BNST-CRF neurons in slices from the GluN2D ${ }^{-7-}$ mice were substantially accelerated compared with those observed in slices from the GluN2D ${ }^{+/+}$mice (Fig. $5 D$; CRF $2 \mathrm{D}^{+/+}: 134.8 \pm 10.1$ half tau [ms], CRF $2 \mathrm{D}^{-1-}: 101.0 \pm 11.9$ half tau $[\mathrm{ms}], t_{(16)}=$ $2.18, p=0.045$, unpaired $t$ test). 

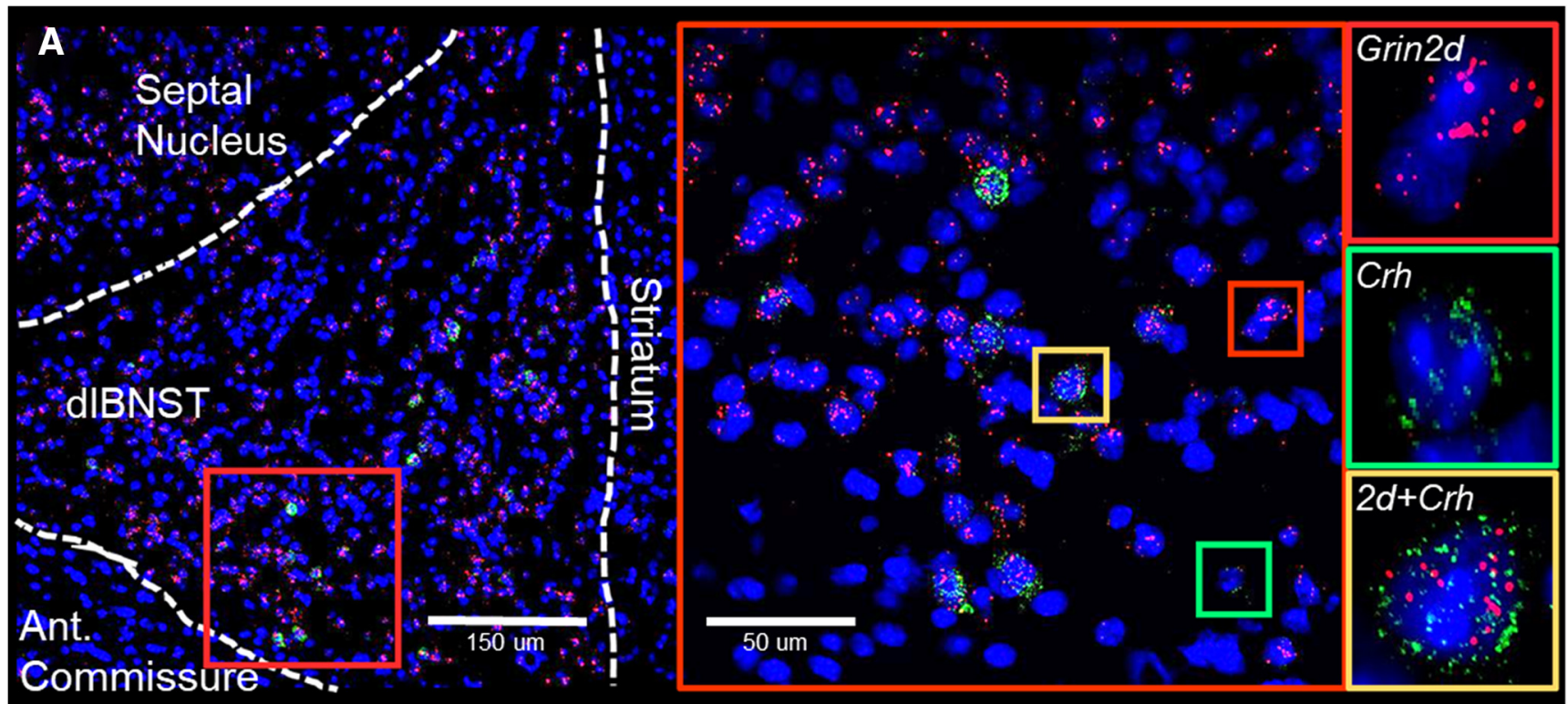

B

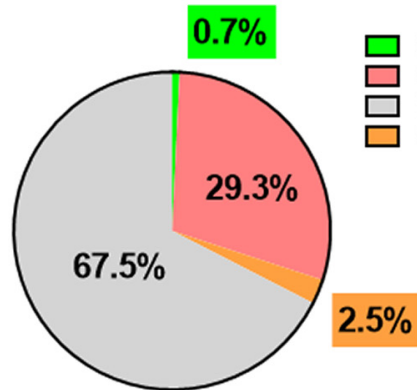

CRF ONLY GIUN2D ONLY Unlabeled GIUN2D/CRF ONLY

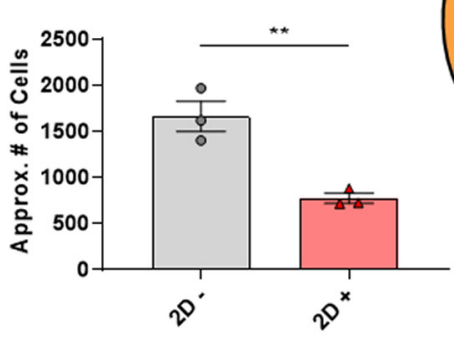

C

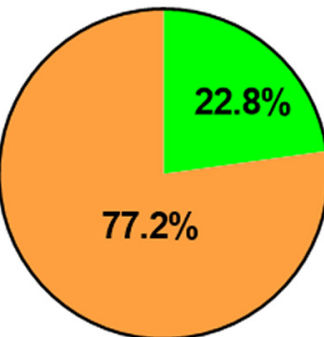

CRF ONLY CRF/GIUN2D

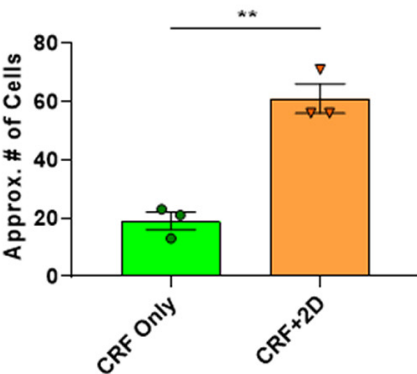

Figure 4. Grin2d mRNA colocalizes with CRF transcripts in dIBNST. $\boldsymbol{A}$, Representative image of the dIBNST (outlined via dashed white lines) at $20 \times$ magnification after undergoing RNAscope (top left), showing individual cells with DAPI (blue) counterstained nuclei labeled for Grin2d (red) or Crh (green) mRNA transcripts. Top right, Red boxed area shows a representative high-magnification image of the dIBNST at $63 \times$, along with example images to the far right of cells labeled for each transcript of interest, and in combination. $\boldsymbol{B}$, Summary graph showing the portion of total counted dIBNST cells (left and right, dIBNST, $N=3$ C57BL/6J mice) labeled for the Grin2d and Crh transcripts alone or in combination. When comparing the total of cells negative for the Grin2d transcript $(2 D[-])$ with those labeled for the transcript $(2 D[+])$, cells positive for GluN2D mRNA are shown to represent a lower population within the dIBNST $(p=$ 0.007). C, Summary graph of the Crh transcript-positive cell populations in the dIBNST. As a portion of these cells, those colabeled for Grin2d are shown to make up a greater overall percentage. Additional comparison of the cells labeled for the Crh transcript alone with those labeled for $C r h$ and Grin2d in combination shows the number of colabeled cells to be significantly higher ( $p=$ 0.002). Data are mean \pm SEM with individual data points overlain. ${ }^{* *} p \leq 0.01$.

\section{Excitatory and inhibitory transmission on BNST-CRF} neurons are divergently controlled by GluN2D

Next, we examined spontaneous excitatory and inhibitory transmission onto BNST-CRF cells in brain slices from GluN2D ${ }^{-1-}$ mice. sEPSC frequency and amplitude were both found to be increased in BNST-CRF neurons from GluN2D ${ }^{-1-}$ slices compared with GluN2D $\mathrm{D}^{+/+}$mice (Fig. $6 A$; frequency: CRF $2 \mathrm{D}^{+/+}: 0.6 \pm 0.1 \mathrm{~Hz}$, CRF 2D $\mathrm{D}^{-1-}: 1.2 \pm 0.2 \mathrm{~Hz}, t_{(28)}=2.73, p=0.011$; amplitude: CRF $2 \mathrm{D}^{+/+}:-23.8 \pm 1.3 \mathrm{pA}, \mathrm{CRF} 2 \mathrm{D}^{-/-}:-29.5 \pm 1.2 \mathrm{pA}, t_{(28)}=$ $3.29, p=0.003$, unpaired $t$ tests). To probe these results further, we repeated this analysis in the presence of the sodium channel blocker TTX $(1 \mu \mathrm{M})$ to remove presynaptic action potential firing and isolate mEPSCs generated by singular vesicle release events. We observed that mEPSC amplitude, but not frequency, was increased on BNST-CRF cells from GluN2D ${ }^{-1-}$ slices in comparison with GluN2D $\mathrm{D}^{+/+}$slices (Fig. $6 B$; frequency: CRF $2 \mathrm{D}^{+/+}: 0.4 \pm 0.01 \mathrm{~Hz}$, $\mathrm{CRF} 2 \mathrm{D}^{+/+}: 0.6 \pm 0.1 \mathrm{~Hz}, t_{(17)}=1.45, p=0.167$; amplitude:
CRF $2 \mathrm{D}^{+/+}:-22.5 \pm 1.1 \mathrm{pA}, \mathrm{CRF} 2 \mathrm{D}^{-/-}:-27.6 \pm 1.2 \mathrm{pA}, t_{(17)}=$ 3.01, $p=0.008$, unpaired $t$ tests). In addition, we analyzed PPRs of electrically evoked EPSCs at $-70 \mathrm{mV}$ across three separate ISIs on BNST-CRF cells in the GluN2D ${ }^{-1-}$, with a two-way ANOVA revealing main effects of ISI time, genotype, and subject (Fig. 6C; ISI time: $F_{(2,32)}=5.62, p=0.008$, genotype: $F_{(1,16)}=34.54$, $p<0.0001$, subject: $F_{(16,32)}=3.58, p=0.001$, ISI time $\times$ genotype: $\left.F_{(2,32)}=2.70, p=0.083\right)$. Post hoc analysis with Sidak's multiple comparisons test showed significantly decreased PPRs $(<1)$ in cells from the GluN2D ${ }^{-/-}$compared with GluN2D ${ }^{+/+}$cells at all time points (30 ms: $p<0.0001$; $50 \mathrm{~ms}: p<0.0001$; $100 \mathrm{~ms}: p=0.005$ ), indicative of paired-pulse depression. Collectively, these results suggest an enhancement of excitatory drive onto BNST-CRF cells in the $\mathrm{KO}$, likely through a combination of presynaptic and postsynaptic mechanisms.

In addition to an analysis of excitatory drive onto BNST-CRF neurons, we assessed the impact of GluN2D deletion on sIPSCs as 

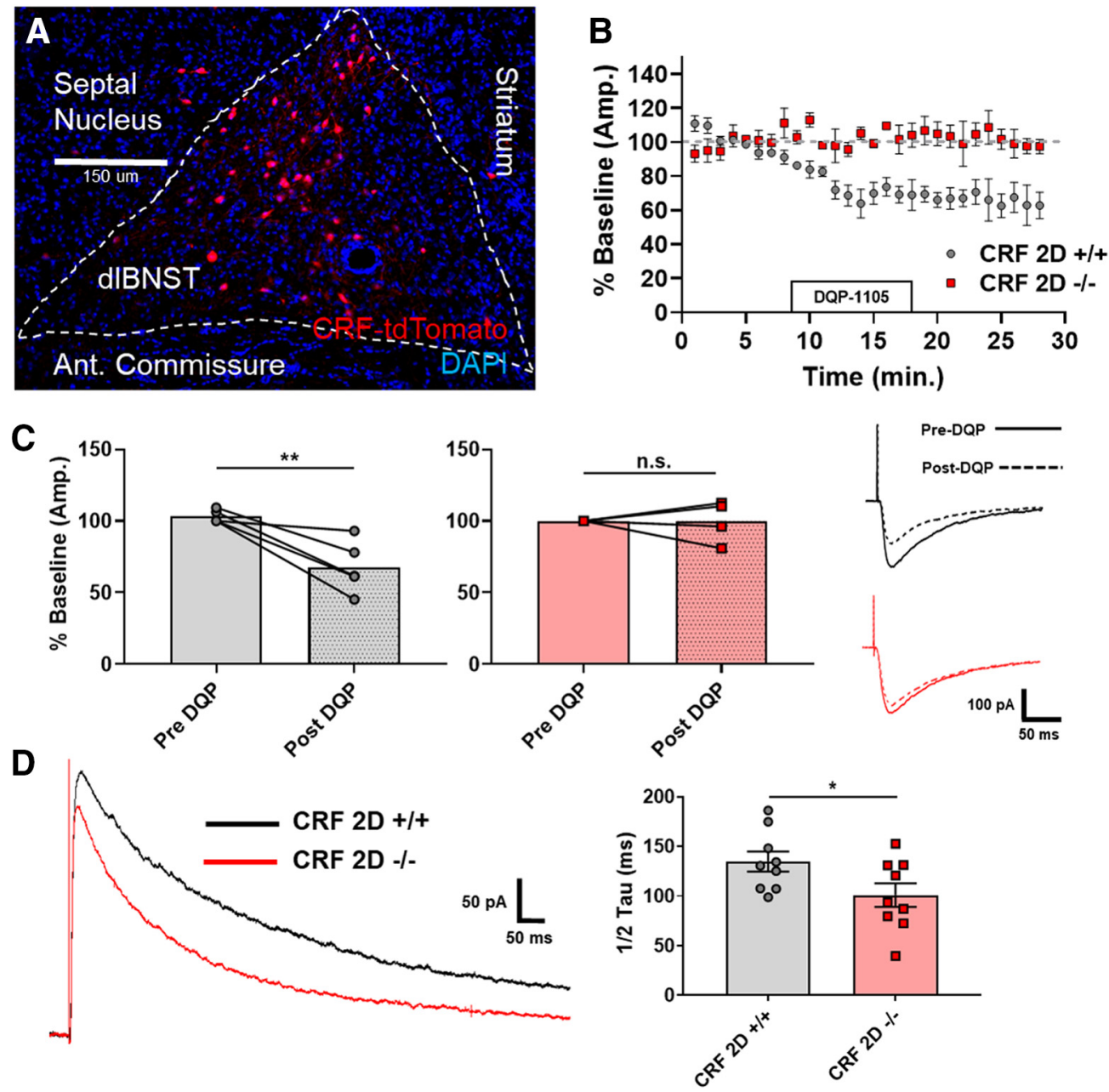

Figure 5. Functional synaptic GluN2D-containing NMDARs are expressed on adult mouse BNST-CRF neurons. $A$, Representative image of the dIBNST (outlined via dashed white lines) from the GluN2D ${ }^{-1-} /$ Crh-IRES-Cre/Ai14 reporter line (CRF 2D ${ }^{-1-}$ ) taken at 20x magnification. Red represents CRF-positive cells labeled with tdTomato. Blue represents cell nuclei denoted by DAPI counterstaining. $B$, Averaged time courses of isolated NMDAR-EPSCs (holding potential: $-70 \mathrm{mV}$, modified $0 \mathrm{Mg}^{2+}$ ACSF) recorded from CRF $2 \mathrm{D}^{+/+}$and CRF $2 \mathrm{D}^{-1-}$ cells in the dIBNST. Bath application of the GluN2C/GluN2D selective antagonist DQP-1105 $(40 \mu \mathrm{M})$ reduced the amplitude of the NMDAR-EPSC only in BNST-CRF $2 D^{+/+}$cells $(35.3 \% \pm 8.4 \%$ decrease from baseline). C, Summary graphs for NMDAR-EPSC amplitude from BNST-CRF $2 D^{+/+}(p=0.003)$ and $2 D^{-1-}(p=0.997)$ cells comparing the first 8 min of recordings before bath application of DQP-1105 (baseline, pre-DQP) and the last 8 min of the recording following both 10 min wash-on of the drug, and a 10 min wash-out (post-DQP). Right, Representative traces pre-DQP (solid line) and post-DQP (dashed line). Data are mean \pm SEM, with individual points overlain ( $\mathrm{n}_{\mathrm{CRF} 2 \mathrm{D}^{+/+}}=5$ cells from $\mathrm{N}_{\mathrm{CRF} 2 \mathrm{D}^{+/+}}=3$ mice, $\mathrm{n}_{\mathrm{CRF} 2 \mathrm{D}^{-/-}}=4$ cells from $\mathrm{N}_{\mathrm{CRF} 2 \mathrm{D}^{-/-}}=2 \mathrm{mice}$ ). $\boldsymbol{D}$, Left, Representative traces of electrically isolated NMDAR-EPSCS (holding potential: $40 \mathrm{mV}$ ) recorded from BNST-CRF $2 D^{+/+}$and $2 D^{-l-}$ cells. Right, Analysis of the overall decay kinetics of the NMDAR-EPSC across both groups revealed a significant decrease in half tau (milliseconds) value for BNST-CRF $2 D^{-1-}$ cells compared with $2 D^{+/+}(p=0.045)$. Data are mean \pm SEM, with individual points overlain ( $\mathrm{n}_{\mathrm{CRF} 2 \mathrm{D}^{+/+}}=9$ cells from $\mathrm{N}_{\mathrm{CRF} 2 \mathrm{D}^{+/+}}=2$ mice, $\mathrm{n}_{\mathrm{CRF} 2 \mathrm{D}^{-/-}}=9$ cells from $\mathrm{N}_{\mathrm{CRF} 2 \mathrm{D}^{-/-}}=2$ mice). ${ }^{*} p \leq 0.05,{ }^{* *} p \leq 0.01$. n.s., not significant.

well. We observed that, in contrast to our sEPSC findings, sIPSC amplitude was decreased onto BNST-CRF neurons in slices from the GluN2D ${ }^{-1-}$ mice compared with the GluN2D ${ }^{+/+}$, whereas frequency was not altered (Fig. $6 D$; frequency: CRF $2 \mathrm{D}^{+/+}$: $1.4 \pm 0.2 \mathrm{~Hz}, \mathrm{CRF} 2 \mathrm{D}^{-l-}: 1.6 \pm 0.3 \mathrm{~Hz}, t_{(28)}=0.77, p=0.447$; amplitude: CRF $2 \mathrm{D}^{+/+}:-24.6 \pm 1.7 \mathrm{pA}, \mathrm{CRF} 2 \mathrm{D}^{-/-}:-19.3 \pm 0.8 \mathrm{pA}$, $t_{(30)}=2.79, p=0.009$, unpaired $t$ tests).

\section{BNST-CRF cells in the GluN2D ${ }^{-/-}$show evidence of increased activity in vivo}

Our observations that excitatory and inhibitory drive onto BNST-CRF neurons are altered in an opposing fashion by the loss of GluN2D-NMDARs suggested the possibility that these cells may exhibit increased activity in vivo in response to such changes in intra-BNST circuit dynamics. We tested this hypothesis by conducting in vivo recordings of neuronal activity from awake, behaving mice via fiber photometry. To generate the necessary transgenic animals, we crossed our GluN2D $\mathrm{D}^{-/-}$mice to the an Crh-IRES-Cre line, then injected Cre-dependent virus transducing the expression of the calcium-sensor GCaMP7f under control of the hSyn promoter unilaterally into the dlBNST, and last implanted the mice with a fiberoptic cable to allow for the detection of GCaMP fluorescence (Fig. 7A). We then examined the basal activity of BNST-CRF cells in both GluN2D ${ }^{+/+}$and GluN2D ${ }^{-l-}$ mice after placing them in a novel, open arena (Fig. $7 B-D$ ). We recorded GCaMP7f signal for $30 \mathrm{~min}$, after which the collected signal was processed and normalized to produce traces showing changes in net fluorescence over time $(\Delta \mathrm{F} / \mathrm{F})$. Neuronal activity was interpreted as imputed calcium-mediated transients (i.e., events) detectable above noise in a trace, and total events were quantified over the course of each recording to examine event frequency. Under basal conditions when exploring a novel environment, we observed a significant increase in the frequency of events recorded from the BNST-CRF cells of GluN2 $\mathrm{D}^{-1-}$ mice compared with GluN2D $\mathrm{D}^{+/+}$(Fig. 7C,D; CRF $2 \mathrm{D}^{+/+}: 0.09 \pm$ $0.01 \mathrm{~Hz}, \mathrm{CRF} 2 \mathrm{D}^{-1-}: 0.11 \pm 0.004 \mathrm{~Hz}, t_{(14)}=2.54, p=0.024$, 
A

Spontaneous EPSC Recordings

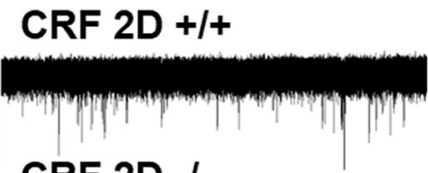

CRF 2D -/-

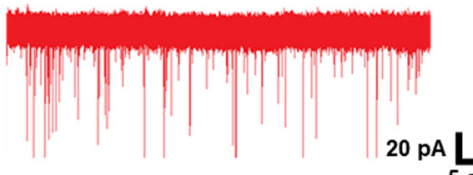

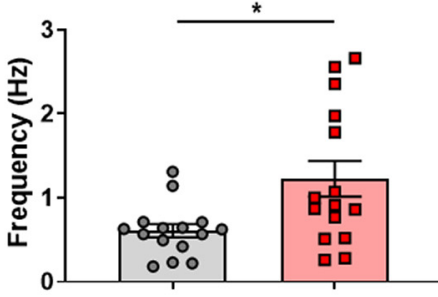

$c^{\alpha^{2}} e^{x^{x^{x}}} \quad c^{\alpha^{x^{2}}}$
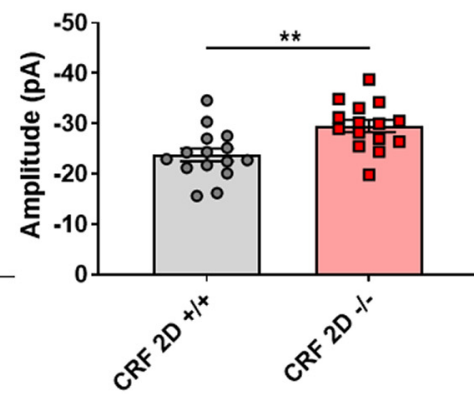

B

\section{Miniature EPSC Recordings}
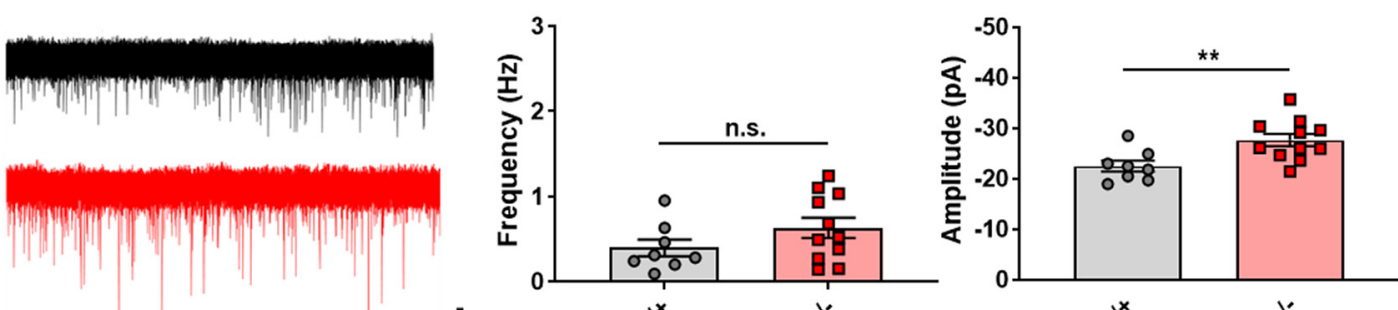

$20 \mathrm{pA} \mathrm{L}$

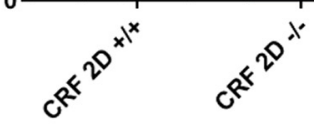

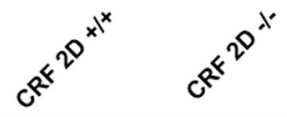

C

Paired Pulse Ratio
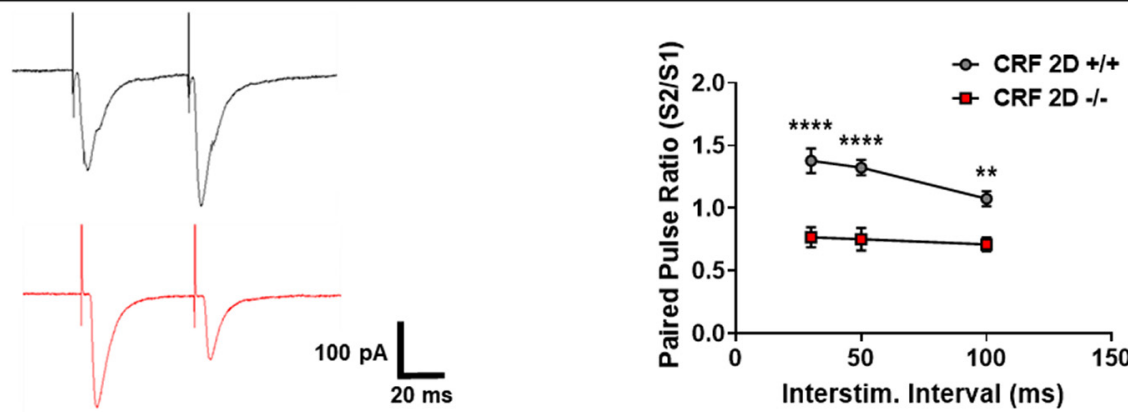

D Spontaneous IPSC Recordings
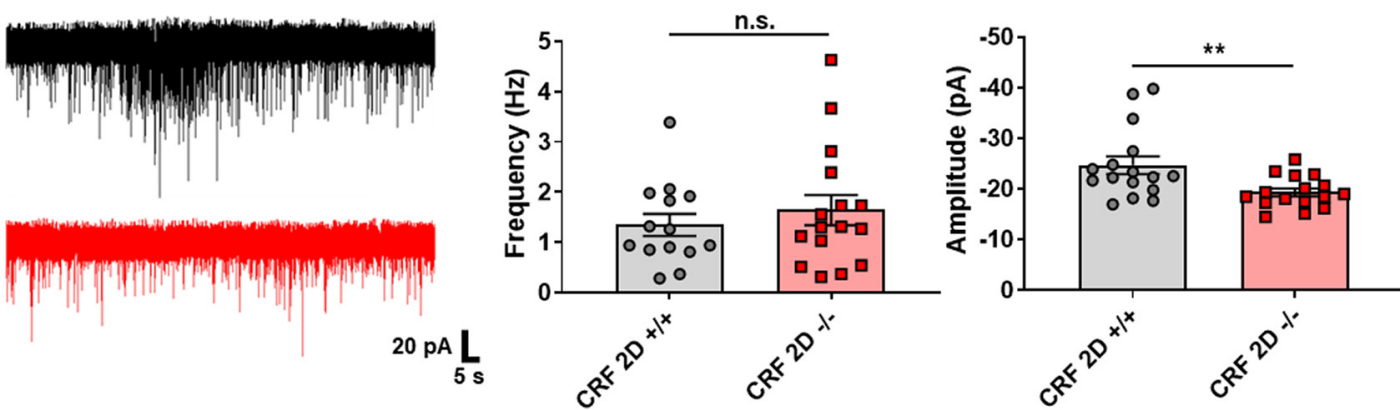

Figure 6. Excitatory and inhibitory transmission on BNST-CRF neurons are divergently controlled by GluN2D. $A$, Representative traces of $s E P S C S$ recorded from BNST-CRF $2 D^{+/+}$(black) and $2 D^{-1-}$ (red) cells (left). Both sEPSC frequency and amplitude were shown to be significantly increased in BNST-CRF $2 D^{-1-}$ cells compared with $2 D^{+/+}$cells (frequency: $p=0.011$, amplitude:

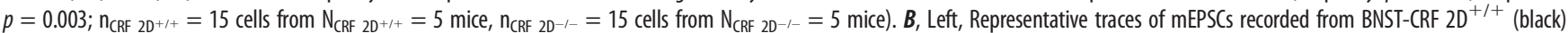
and $2 D^{-1-}$ (red) cells. No differences were noted in the frequency of mEPSCs in BNST-CRF $2 D^{+/+}$or $2 D^{-1-}$ cells, but amplitude was found to be significantly increased in the $2 D^{-1-}$ cells (frequency: $p=0.167$, amplitude: $p=0.008 ; \mathrm{n}_{\mathrm{CRF}_{2 \mathrm{D}^{+/+}}}=8$ cells from $\mathrm{N}_{\mathrm{CRF} 2 \mathrm{D}^{+/+}}=4$ mice, $\mathrm{n}_{\mathrm{CRF} 2 \mathrm{D}^{-/-}}=11$ cells from $\mathrm{N}_{\mathrm{CRF}_{2 D^{-/-}}}=4$ mice). C, Left, Representative traces of paired EPSCs at an ISI of 50 ms from both BNST-CRF 2D $\mathrm{D}^{+/+}$(black) and $2 \mathrm{D}^{-/-}$(red) cells. Right, PPRs of evoked 100-200 pA responses, elicited at ISI of 30, 50, and $100 \mathrm{~ms}$, show significant decreases in the ratio at all three time points for the CRF $2 D^{-/-}$cells compared with metrics from $2 \mathrm{D}^{+/+}$cells $\left(F_{(2,32)}=5.62, p=0.008 ; \mathrm{n}_{\mathrm{CRF}_{2} \mathrm{D}^{+/+}}=10\right.$ cells from $\mathrm{N}_{\mathrm{CRF} 2 \mathrm{D}^{+/+}}=4$ mice, $\mathrm{n}_{\mathrm{CRF} 2 \mathrm{D}^{-/-}}=8$ cells from $\mathrm{N}_{(\mathrm{RF}} 2 \mathrm{D}^{-/-}=4$ mice). $\boldsymbol{D}$, Left, Representative traces of sIPSCS recorded from BNST-CRF $2 D^{+/+}$(black) and $2 D^{-/-}$(red) cells. No differences were noted in sIPSC frequency between BNST-CRF $2 D^{+/+}$and $2 D^{-1-}$ cells on comparison, but the amplitude of these currents was found to be significantly increased in the $2 D^{-1-}$ (frequency: $p=0.447$, amplitude: $p=0.009$; $\mathrm{n}_{\mathrm{CRF} 2 \mathrm{D}^{+/+}}=14$ cells from $\mathrm{N}_{\mathrm{CRF} 2 \mathrm{D}^{+/+}}=3$ mice, $\mathrm{n}_{\mathrm{CRF} 2 \mathrm{D}^{-/-}}=16$ cells from $\mathrm{N}_{\mathrm{CRF} 2 \mathrm{D}^{-/-}}=4$ mice). All data across graphs are mean \pm SEM with individual points overlain. ${ }^{*} p \leq 0.05$, ${ }^{* *} p \leq 0.01,{ }^{* * *} p \leq 0.0001$. n.S., not significant. 
A

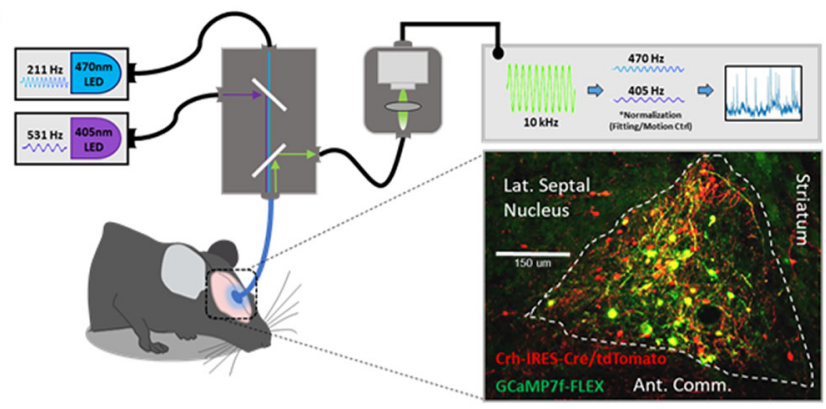

B

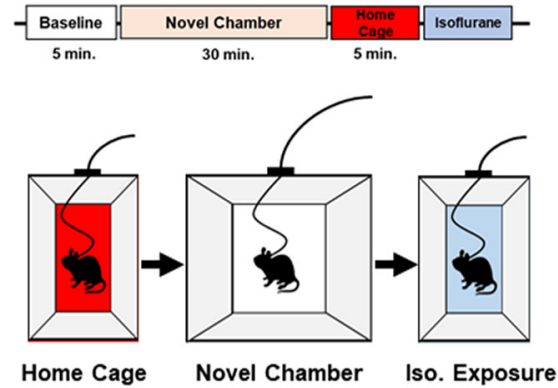

C

CRF 2D +/+

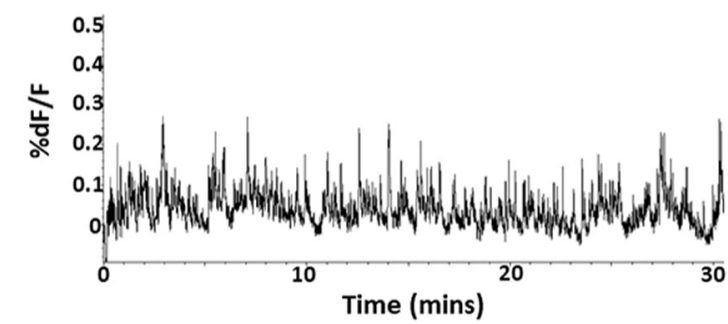

CRF 2D -/-

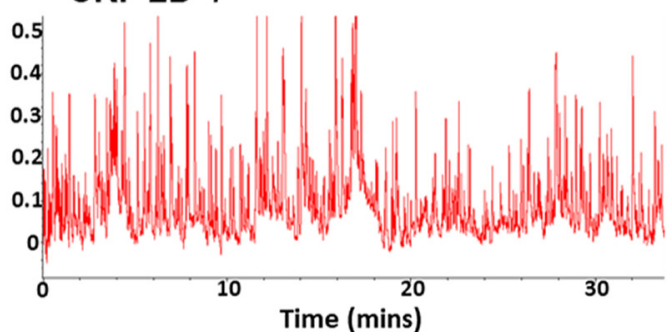

D

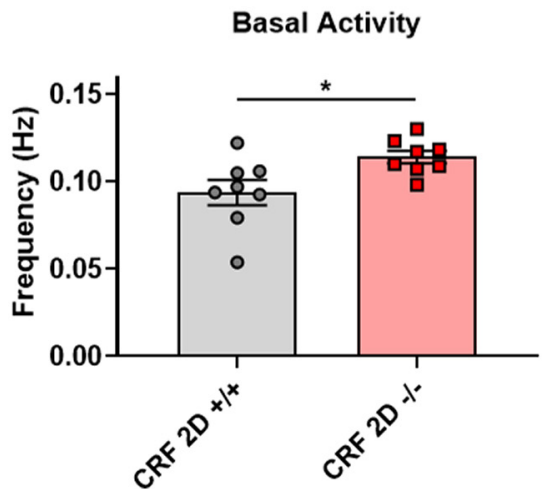

$\mathbf{E}$

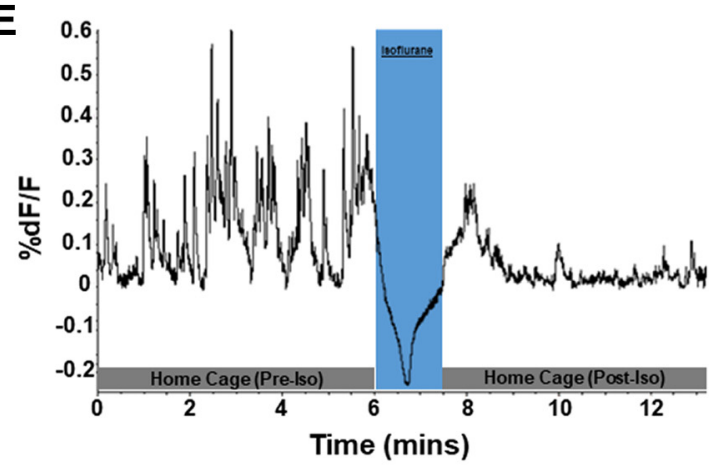

Figure 7. BNST-CRF cells in the GluN2D ${ }^{-1-}$ show evidence of increased activity in vivo. A, Schematic showing setup of in vivo fiber photometry system used for detecting and recording GCaMP7f signaling from CRF-Cre(+) cells in the dIBNST of awaking, behaving GluN2D ${ }^{-1-} /$ Crh-IRES-Cre mice. Bottom right, Representative $20 \times$ magnified image shows the general expression patterns of Crh-IRES-Cre in the dIBNST and coexpression of a Cre-dependent virus encoding GCaMP7f. B, Outline of behavioral testing for recording basal activity of BNST-CRF cells in GluN2D ${ }^{+/+}$ $\left(2 \mathrm{D}^{+/+}\right)$and GluN2D $\mathrm{D}^{-/-}\left(2 \mathrm{D}^{-/-}\right)$mice when placed in a novel environment. A baseline of initial activity in home cages were observed for validating signal output. Select individuals were briefly exposed to isoflurane gas to assess specificity of signal in awake, behaving mice. C, Representative fiber photometry traces showing changes in the basal activity of BNST-CRF cells from both the $2 D^{+/+}$(left, black) and $2 D^{-1-}$ (right, red) mice over a 30 min recording. $D$, Summary graph comparing the frequency of recorded GCaMP7f events from BNST-CRF $2 D^{+/+}$and $2 D^{-/-}$ cells under basal conditions for 30 min. Event frequency was found to be significantly increased in the BNST-CRF cells of the $2 D^{-1-}$ compared with $2 D^{+/+}$controls $(p=0.024)$. Data are mean $\pm \mathrm{SEM}$, with individual data points overlain ( $\mathrm{N}_{\mathrm{BNST}-\mathrm{CRF}} 2 \mathrm{D}^{+/+}=8$ mice, $\mathrm{N}_{\text {BNST-CRF } 2 \mathrm{D}^{-/-}}=8$ mice). Imputed calcium transients are presented as changes in $\mathrm{dF} / \mathrm{F}$. ${ }^{*} p \leq 0.05$. $E$, Specificity of GCaMP7f signal in BNST-CRF $(+)$ cells was tested via brief exposure to isoflurane gas. A representative trace shows recordings from these cells prior to exposure $(\sim 0-6$ min), at the onset of exposure ( $\sim 30$ sec exposure, shaded blue region), and after the mouse was removed from the anesthesia chamber ( $\sim 7 \mathrm{~min}, 30 \mathrm{sec}$ mark) and allowed to regain consciousness in its home cage for an additional 5 mins. No imputed events were detectable during isoflurane exposure.

unpaired $t$ test), consistent with our hypothesis of increased activity of these cells in the $\mathrm{KO}$ in vivo. To validate the fidelity of the recorded GCaMP7f signal observed during this task, we placed mice into an anesthesia chamber following a brief recovery period in their home cages and recorded activity in the BNST during isoflurane exposure (Fig. $7 B, E$ ). A 1 min exposure of isoflurane decreased imputed $\mathrm{Ca}^{2+}$ transients drastically and persisted after the removal of the mice from the chamber until they regained consciousness, after which the signal was restored to basal levels.

BNST specific deletion of the GluN2D subunit produces an enhanced depressive-like phenotype in mice

Our data suggest that the constitutive loss of the GluN2D subunit from NMDARs in adult mice leads to increased negative emotional behavior and associated increases in the activity profiles of BNST-CRF neurons. To more specifically manipulate BNST GluN2D subunits, and control for potential compensatory effects resulting from the loss of a key subunit from birth (Balu and Coyle, 2011), and the differing role in signaling and level of expression of GluN2D-NMDARs, particularly in interneurons, noted in the early stages of development (Monyer et al., 1994; Wenzel et al., 1996; Hanson et al., 2019), we used a GluN2D conditional KO line (GluN2D $\left.{ }^{\mathrm{flx} / \mathrm{flx}}\right)$ to selectively ablate the subunit from the BNST in adult mice. We first tested the efficiency of the GluN2D $\mathrm{D}^{\mathrm{flx} / \mathrm{flx}}$ for knocking down the protein by performing intracranial injections of viruses encoding either Cre or eGFP bilaterally into the dlBNST (Fig. $8 A$, middle) and then collecting tissue punches from BNST for Western blot analysis using whole tissue lysates. Samples from Cre-injected mice revealed a robust knockdown of GluN2D, as evidenced by the lack of a band 
for the protein across all relevant samples (Fig. $8 A$, right). By comparison, BNST samples from eGFP-injected controls still displayed a prominent band for GluN2D, while additional samples taken from the thalamus of BNST-Cre injected mice also showed a robust band, further confirming the selectively of the GluN2D ${ }^{\text {flx } / \mathrm{flx}}$ line.

We repeated the behavioral studies we ran on our GluN2D ${ }^{-1-}$ mice across cohorts of age-matched ( $\sim 12$ weeks $)$ male GluN2D ${ }^{\text {flx/flx }}$ following intracranial injection of either Cre or eGFP encoding virus bilaterally into the dlBNST (Fig. 8B,C). Analysis of total center time in the OFT revealed no difference in the percent total time spent in the center of the chamber between Cre- or eGFP-injected mice (Fig. 8C, left, left middle; $2 \mathrm{D}^{\mathrm{flx} / \mathrm{flx} \text {-eGFP }}: 57.2 \pm 7.2 \%$ time in center, $2 \mathrm{D}^{\mathrm{flx} / \mathrm{flx}-\mathrm{Cre}}: 46.6 \pm 4.4 \%$ time in center, $t_{(21)}=1.29, p=0.212$, unpaired $t$ test), as well as no overt differences in locomotor activity across all time points (Fig. 8C, left; locomotion: $F_{(1,21)}=1.28, p=0.271$, two-way ANOVA with Sidak's repeated-measures post hoc test). We also noted no difference in the total percent time spent in the open quadrants of the EZM when running both Cre and eGFP injected mice in this task (Fig. $8 C$, right center; $2 \mathrm{D}^{\mathrm{flx} / \mathrm{flx} \text {-eGFP }}$ $40.8 \pm 7.1 \%$ time in middle, $2 \mathrm{D}^{\mathrm{flx} / \mathrm{flx}-\mathrm{Cre}}: 32.7 \pm 3.9 \%$ time in center, $t_{(21)}=1.03, p=0.317$, unpaired $t$ test), indicating along with the results of the OFT an apparent lack of increased anxiety-like behavior. By contrast, the FST revealed a significant increase in the total immobility time for Cre-injected mice compared with eGFP injected controls (Fig. $8 C$, right; $2 \mathrm{D}^{\mathrm{flx} / \mathrm{flx}-\mathrm{eGFP}}: 62.9 \pm 10.7 \mathrm{~s}$ immobile, $2 \mathrm{D}^{\mathrm{flx} / \mathrm{flx}-\mathrm{Cre}}: 108.2 \pm 13.2 \mathrm{~s}$ immobile, $t_{(21)}=2.63, p=$ $0.016)$, suggesting a possible increase in depressive-like behavior similar to what we observed in the constitutive KOs. To further assess this phenotype, we tested a new cohort of mice on the $\mathrm{NIH}$ task to assess the latency to consume a highly palatable food (Fig. 8D) (Dulawa and Hen, 2005; Louderback et al., 2013). Creinjected mice demonstrated an increase in their overall latency to first approaching and licking sipper bottles containing Ensure compared with eGFP-injected control littermates (Fig. 8D, left middle; $2 \mathrm{D}^{\text {flx/flx-eGFP }}: 167.8 \pm 45.7 \mathrm{~s}$ [latency to lick], 2D ${ }^{\text {flx/flx-Cre }}$ : $417.6 \pm 99.4 \mathrm{~s}$ [latency to lick], $t_{(19)}=2.21, p=0.04$, unpaired $t$ test). Analysis of the overall acquisition of the task and total Ensure consumption were also tracked across groups for the duration of the NIH, and showed no differences in the initial ability of the mice to learn to drink the Ensure (Fig. $8 D$, left; latency: $F_{(1,19)}=2.135, p=0.16$, subject: $F_{(19,76)}=1.472, p=0.121$, twoway ANOVA with Sidak's repeated measures post hoc test) or amount of Ensure consumed across all days (Fig. 8D, right middle; consumption time course, latency: $F_{(1,19)}=0.02, p=0.90$, day $\times$ latency: $F_{(4,76)}=0.69, p=0.601$, two-way ANOVA with Sidak's multiple comparisons post hoc test; test day consumption: $2 \mathrm{D}^{\mathrm{flx} / \mathrm{flx}-\mathrm{eGFP}}: 0.97 \pm 0.1$ consumed $[\mathrm{g}], 2 \mathrm{D}^{\mathrm{flx} / \mathrm{flx}-\mathrm{Cre}}: 0.9 \pm 0.1$ consumed $[\mathrm{g}], t_{(19)}=0.95, p=0.354$, unpaired $t$ test).

\section{BNST specific deletion of GluN2D produces increased excitatory drive onto BNST-CRF neurons}

To better clarify the effects, we observed on BNST-CRF neuron excitability in the GluN2D ${ }^{-/} /$Crf-Tomato line, we crossed the GluN2D ${ }^{\mathrm{flx} / \mathrm{fl} \mathrm{x}}$ mice with a line expressing Flp recombinase (CrhIRES-FlpO) under the control of the Crh promoter $\left(G l u N 2 D^{f l x / f l x} /\right.$ Crf-Flp) to allow for CRF cell-specific recordings in the BNST following GluN2D deletion. Using RNAscope, we examined transcript expression patterns and colocalization across the left and right dlBNST of 7 separate adult Crh-IRES-FlpO mice for both Crh and Flp cDNA to validate the fidelity and penetrance of Flp expression in BNST-CRF cells. We found the probes to show a high level of colocalization with one another in the dlBNST, with minimal ectopic expression of signal for the Flp probe on cells negative for the Crh probe (Fig. 9A; penetrance: $\mathrm{Crh}[+]$ only $=227$ cells, $\sim 25.8 \%$ of total Crh $[+]$ cells, Crh $[+] /$ Flp $[+]=$ 654 cells, $\sim 74.2 \%$ of total $\mathrm{Crh}[+]$ cells; fidelity: Flp $[+]$ only $=$ $44, \sim 6.3 \%$ of total Flp $[+]$ cells, Flp $[+] / \mathrm{Crh}[+]=654$ cells, $\sim 93.7 \%$ of total Flp $[+]$ cells; lower insert left, Crh cell average totals: $t_{(12)}=2.48, p=0.029$; lower insert right, Flp cell average totals: $t_{(12)}=3.87, p=0.002$, unpaired $t$ tests), indicating that the majority of BNST-CRF-positive cells in these mice are Flp-positive as well. Following this confirmation, GluN2D ${ }^{\mathrm{flx} / \mathrm{flx}} / \mathrm{Crf}-\mathrm{Flp}$ mice were intracranially injected with viruses encoding Cre tagged with an eGFP reporter and Flp-dependent tdTomato into the BNST, allowing us to both identify and patch tdTomato-positive (i.e., CRF-positive) Cre-positive $(\mathrm{Cre}[+])$ or Cre-negative (Cre[-]) cells in ex vivo slices (Fig. 9B). Using this approach, we first confirmed NMDAR function to be altered in Cre $(+)$ cells compared with $\mathrm{Cre}(-)$ cells by examining isolated NMDAR eEPSC decay kinetics, and noted a significant increase in the decay rate in $\mathrm{Cre}(+)$ comparable with what we found when recording from BNST-CRF cells in the GluN2D ${ }^{-1-}$ line (Fig. 9C; Cre[-] $=58.8 \pm 5.8 \mathrm{~ms}$, Cre $[+]=39.2 \pm 5.4 \mathrm{~ms}, t_{(13)}=2.48, p=$ 0.028 , unpaired $t$ test). We then recorded sEPSCs for both Cre $(+)$ and Cre(-) cells, and observed a significant increase in the frequency of these events in $\mathrm{Cre}(+)$ cells, as well as a nonsignificant increase in the sEPSC amplitude (Fig. 9D; frequency: Cre[-] $=1.3 \pm 0.4 \mathrm{~Hz}, \mathrm{Cre}[+]=3.6 \pm 0.8 \mathrm{~Hz}, t_{(18)}=2.59, p=0.019$, unpaired $t$ test; amplitude: Cre[-] $=-26.5 \pm 1.4 \mathrm{pA}$, Cre[+] $=$ $-32.2 \pm 2.4 \mathrm{pA}, t_{(18)}=2.08, p=0.053$, unpaired $t$ test). Together, these data demonstrate an enhancement of excitatory drive onto BNST-CRF cells that occurs following acute deletion of GluN2D-NMDARs in the BNST similar to what we reported in the case of the GluN2D $\mathrm{D}^{-1-}$. This further indicates a key role for these receptors in regulating intra-BNST excitatory signaling, specifically on select subpopulations of BNST cells.

\section{Discussion}

Here, we demonstrate a role for GluN2D-NMDARs in both modulating emotional behaviors and regulating BNST neuronal activity. We find that GluN2D deletion promotes an increase in anxiety- and depressive-like behavior, consistent with previous studies (Yamamoto et al., 2017; Shelkar et al., 2019). Using ex vivo electrophysiology and in vivo photometry, we identified adaptations in the BNST that correlate with these behaviors via enhanced excitatory drive and basal activation of BNST-CRFpositive cells. Further, through the use of a novel GluN2D ${ }^{\text {flx/flx }}$ line, we demonstrate a direct link between the loss of GluN2DNMDAR function in the BNST and increased depressive-like behavior. Ex vivo recordings from the BNST in these mice show similar increases in excitatory drive onto CRF cells, an effect that may correlate with the enhanced negative emotional state these mice display. Collectively, our findings suggest the GluN2DNMDARs as an intriguing target for modulating glutamatergic signaling in key stress-responsive cell populations.

\section{GluN2D-NMDAR expression in the BNST and emotional behavior}

The BNST receives glutamatergic projections from several structures implicated in the regulation of emotional behavior, and deficits in BNST excitatory signaling have consistently been shown to be linked with increases in negative emotional behavior (McElligott and Winder, 2009; Conrad and Winder, 2011; 
A
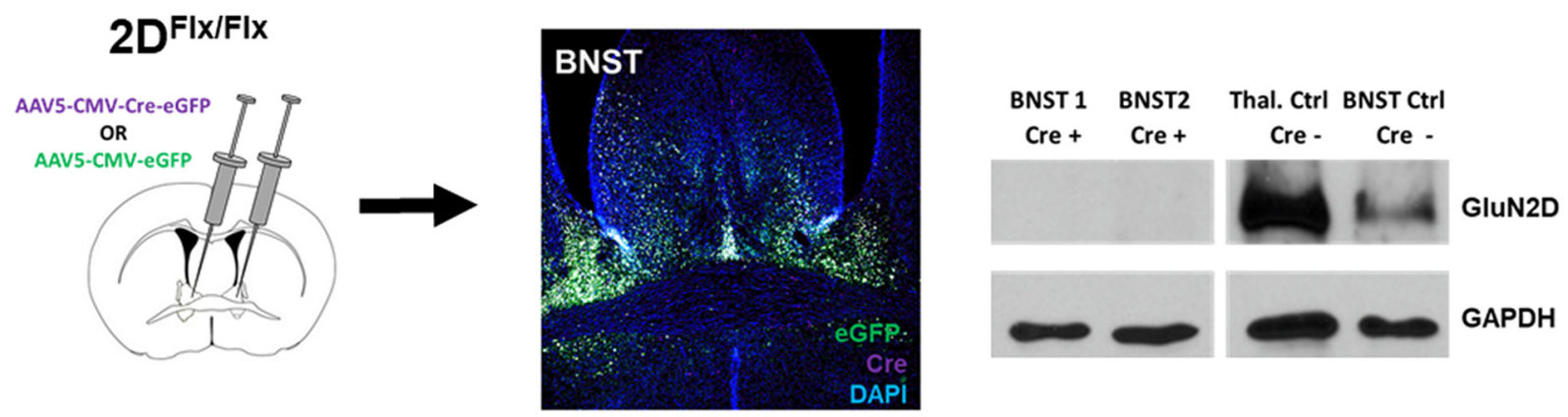

B

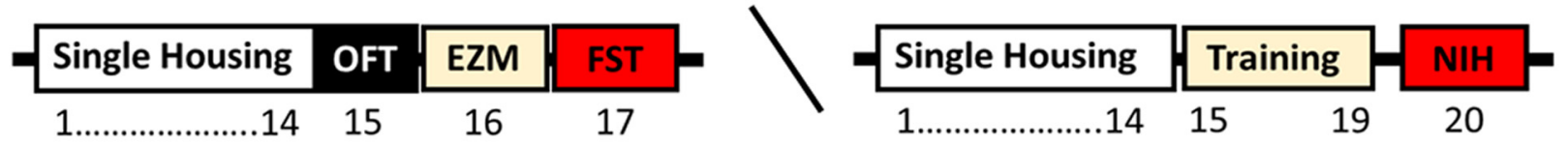

C

Behavior Battery (OFT, EZM, FST)
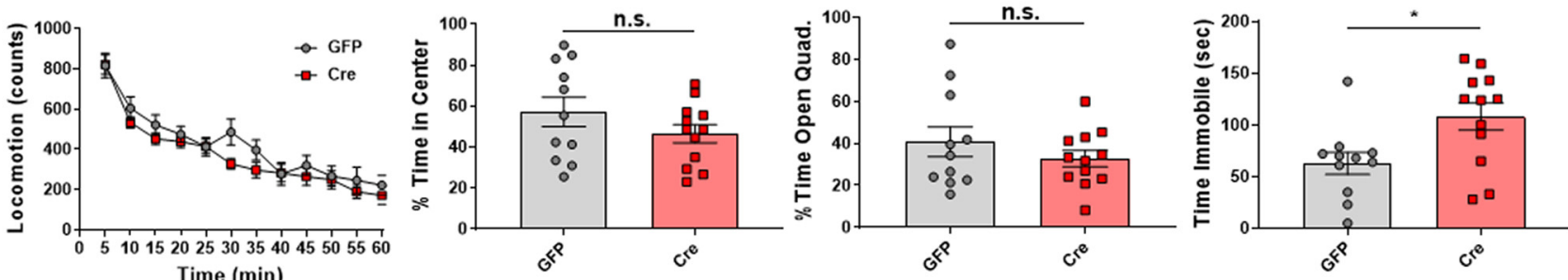

D

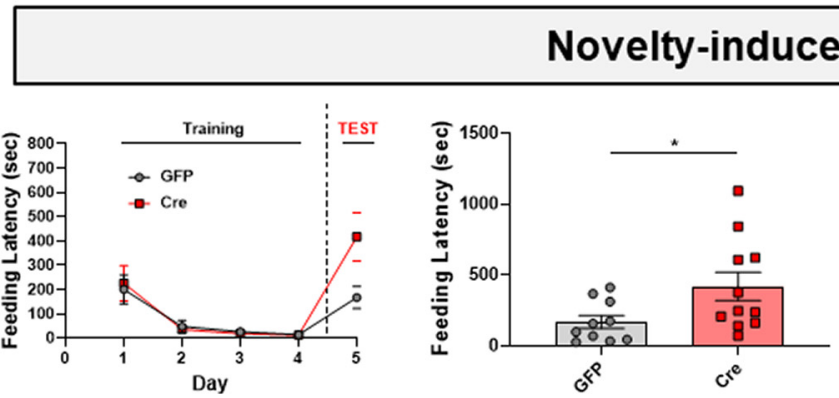

Novelty-induced Hypophagia

Figure 8. Conditional deletion of GluN2D in the BNST produces an increase in depressive-like behaviors in mice. $A$, Left, Schematic of mouse surgery and viral injection paradigms for driving either Cre or eGFP expression bilaterally in the dIBNST of GluN2D flxflx mice. Representative $5 \times$ image (middle) showing expression patterns of (re (magenta), eGFP (green), and DAPI counterstaining (blue) in the dIBNST $\sim 4-5$ weeks after surgery. Western blot analysis of total protein lysate taken from tissue punches (0.08 mm) of the dIBNST following either Cre (Cre[+]) or control/sham injection (Cre[-]). Representative blot of bands for both GluN2D and control GAPDH for Cre-injected mice (left) and controls (right) show robust knockdown of subunit expression in the conditional line when Cre is present. Control punches were taken from the medial thalamus of BNST-injected mice as well to verify specificity of targeted deletion. $\boldsymbol{B}$, Design schema and timeline for modified $3 \mathrm{~d}$ behavioral testing battery, consisting of the OFT, EZM, and FST, and a separate timeline for the NIH. C, Behavioral testing results comparing anxiety- and depressivelike behaviors of GluN2D $D^{\text {flxfflx }}$ mice following bilateral BNST KO of GluN2D (Cre) or control virus injection (eGFP). Analysis of percent total center time in the OFT revealed no significance difference in behavior in either Cre- or eGPF-injected individuals (left center), as well as no observable differences in locomotor activity between groups during the 60 min task (left, locomotor activity: $F_{(1,21)}=1.28, p=0.271$; middle, time: $p=0.212$ ). Analysis of percent total time in the open quadrants of the EZM in both Cre- and eGFP-injected mice also showed no significant differences in anxiety-related behaviors (right middle, $p=0.317$ ). Total immobility time in the FST was, however, found to be significantly increased in Cre-injected individuals compared with eGFP-injected controls (right, $p=0.016$ ). $\boldsymbol{D}$, A separate cohort of mice were run on the NIH as an additional measure of depressive-like behaviors. No overt differences in ability to acquire the drinking paradigm was observed between groups (left, latency: $\left.F_{(1,19)}=2.14, p=0.16\right)$, but Cre-injected mice displayed a significant increase in the total time (seconds) taken to first approaching and drinking sippers of Ensure in a novel, brightly lit cage compared with eGFP-injected controls (left, $p=0.04$ ). Both groups also showed no difference in total Ensure consumption across days or amount of Ensure consumed on test day (latency course: $F_{(1,19)}=0.02, p=0.902$, day $\times$ latency: $F_{(4,76)}=0.69, p=0.601$; test day consumption: $\left.p=0.354\right)$. Data are mean \pm SEM, with individual data points overlain $\left(\mathrm{N}_{\text {GluN2D }}{ }_{\text {fl/ffix-eGFP }}=11\right.$ mice, $\mathrm{N}_{\text {GluN2D }}{ }_{\text {flfflx-Cre }}=12$ mice). ${ }^{*} p \leq 0.05$. n.s., not significant.

Conrad et al., 2011; Lebow and Chen, 2016; Glangetas et al., 2017; Ch'ng et al., 2018). Studies have also implicated NMDARmediated signaling in the BNST as important to the regulation of these emotional states, with Glangetas et al. (2017) demonstrating that the inhibition of an NMDAR-mediated form of LTP in the vHipp-BNST circuit promotes anxiogenic behavior in the
EPM. Previous studies have shown GluN2D to be enriched in midbrain and hindbrain structures in adult rodents (Monyer et al., 1994; Wenzel et al., 1996), and we provide evidence here for the subunit's expression in the BNST of adult mice. We further show a basal disruption of STP in the BNST of the GluN2D ${ }^{-1-}$, resulting in an acute blunting of synaptic potentiation. GluN2D 
A
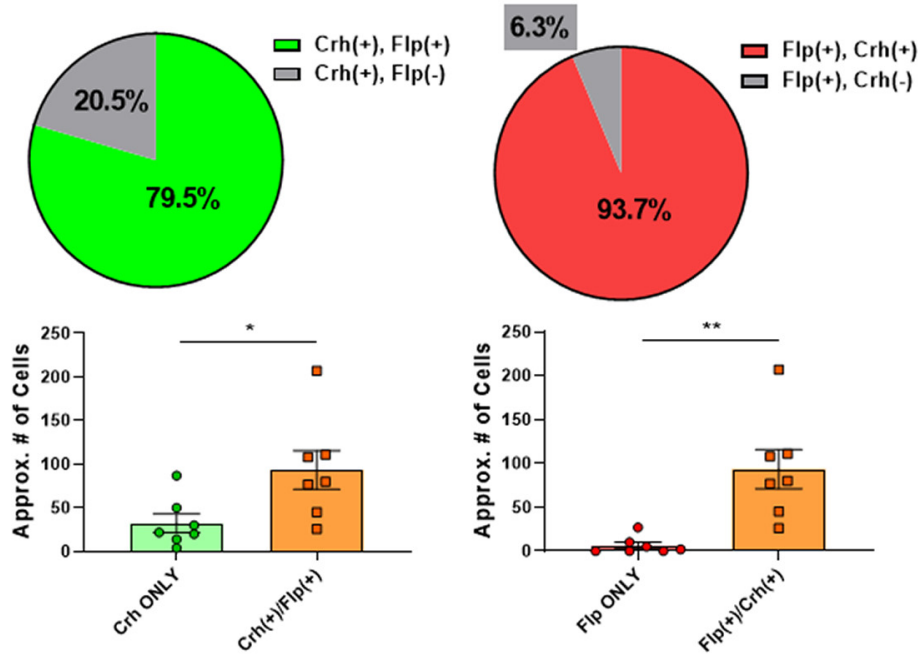

B

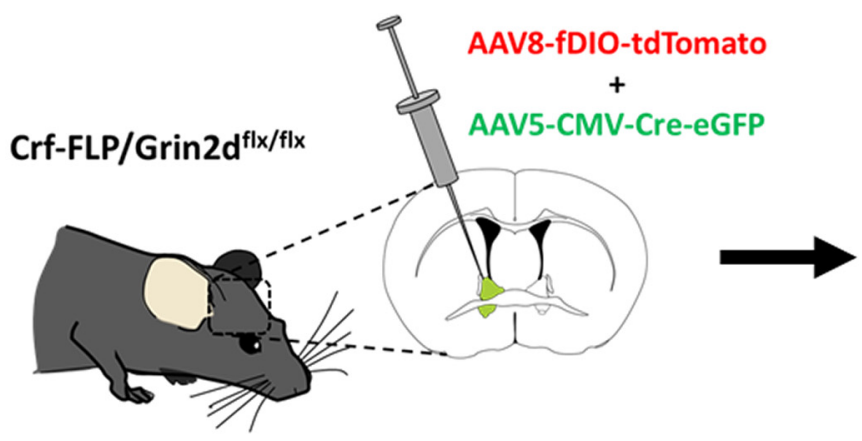

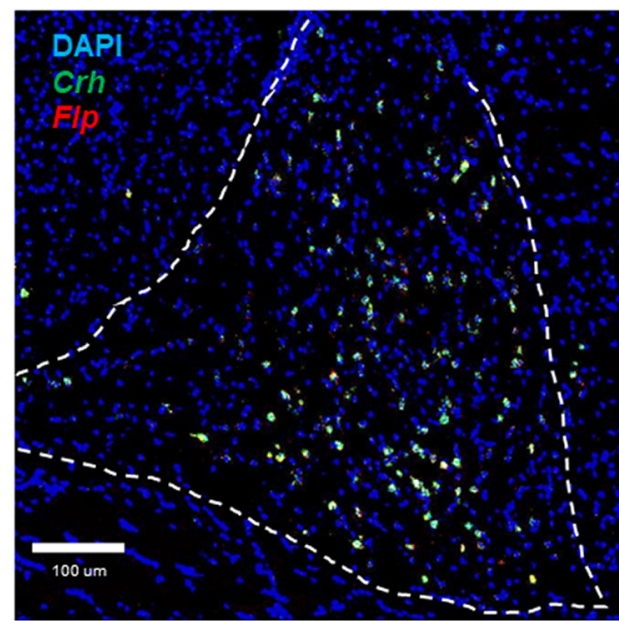

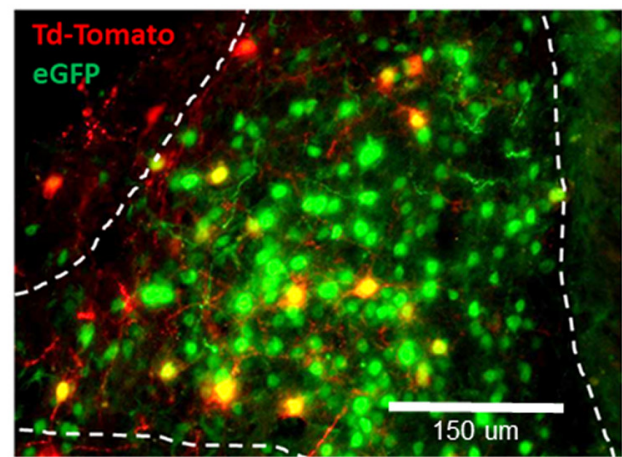

C
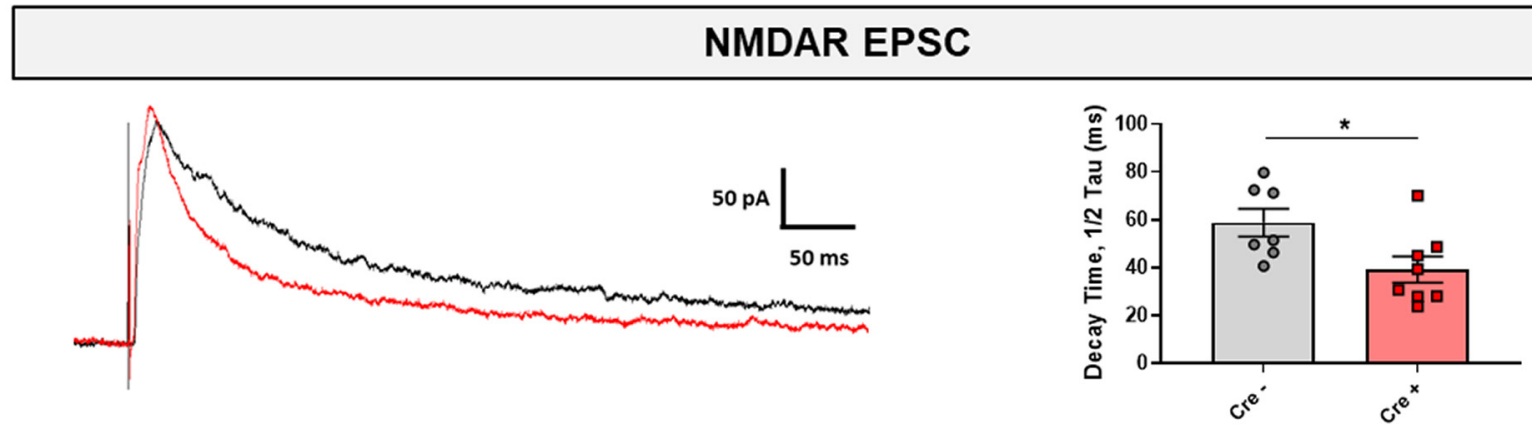

D
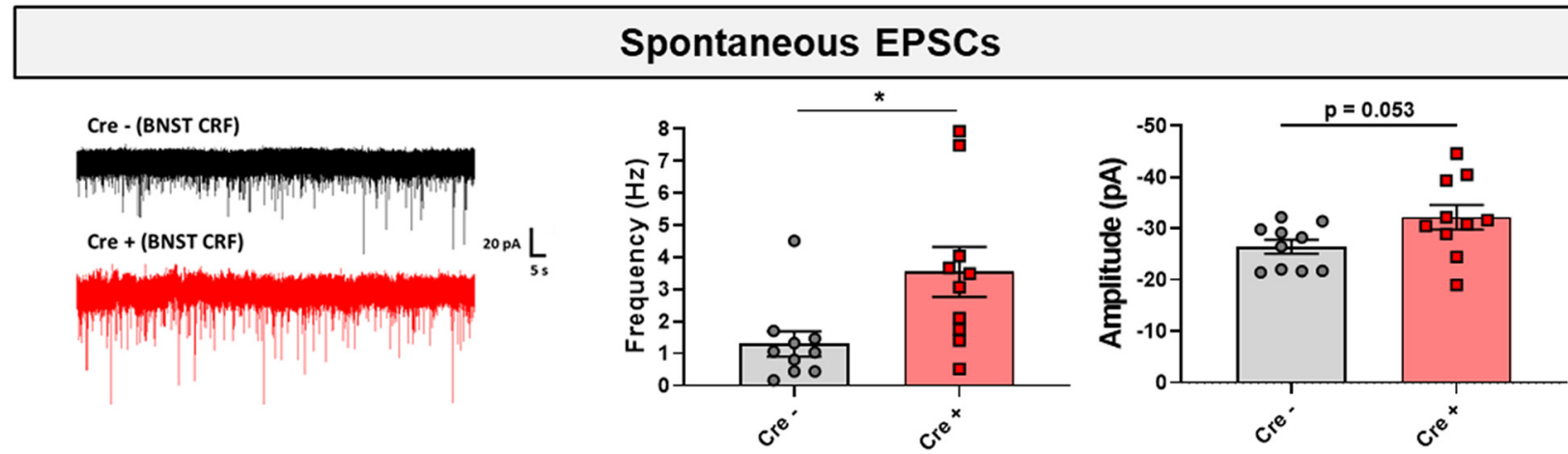

Figure 9. Region-specific deletion of GluN2D in dIBNST produces increased excitatory drive onto CRF cells and altered NMDAR kinetics. $\boldsymbol{A}$, Representative image of the dIBNST (outlined via dashed white lines) at 20× magnification after undergoing RNAscope (right), showing individual cells with DAPI (blue) counterstained nuclei labeled for Crh (green) or Flp (red) mRNA transcripts. Summary graphs (left) showing the portion of total counted dIBNST cells (left, right, dIBNST, $N=7$ Crh-IRES-Flp0 mice) labeled for the Crh and Flp transcripts alone or in combination. When comparing the total of cells negative for the Crh transcript (Crh Only) to those labeled for both transcripts (Crh[ +$] \mathrm{NFlp}[+])$, cells positive for both are shown to represent the majority of $\mathrm{Crh}(+)$ cells labeled within the dIBNST and averaged counts of cells from both left and right dIBNST across all mice confirms the high penetrance of Flp expression in this population ( $p=$ 0.029). Similar results are also shown for Flp $(+)$ cells when confirming the fidelity of Flp expression in $\mathrm{Crh}(+)$ cells, showing only minimal ectopic Flp expression outside of $\mathrm{Crh}(+)$ cells $(p=$ 0.002). B, Schematic outlining surgery and viral injection strategy for region-specific ablation of GluN2D in the dIBNST and identification of BNST-CRF cells in slices during whole-cell patchclamp recordings using a coinjection of Flp-dependent tdTomato and Cre virus (1:1 mix). A representative $20 \times$ image of both eGFP-labeled Cre-positive cells (green) and tdTomato-labeled cells 
deletion or pharmacological inhibition has previously been found to produce similar reductions in forms of hippocampal STP, demonstrating a conserved role for GluN2D-NMDARs in the control of short-term plasticity (Volianskis et al., 2013, 2015). A correlation may thus exist between the deficits in BNST plasticity and enhanced negative emotional state we observed in the GluN2D ${ }^{-1-}$, and is supported by work from Conrad et al. (2011), in which mice that presented with a heightened anxiogenic state following chronic stress were shown to have a blunting of LTP in the BNST. Whether such parallel changes in both behavior and BNST plasticity are predicated on reduced GluN2D-NMDAR function will require more directed and in-depth study, specifically in regard to whether real-time disruption of receptor function can drive changes in emotional behavior in awake, behaving mice. Nevertheless, our work here presents important initial evidence for both the expression and function of GluN2DNMDARs in the BNST of adult mice, and positions this receptor population as a potential key player in the maintenance of plasticity events relevant to emotional behavioral output.

\section{GluN2D-NMDAR-mediated signaling and CRF neuronal activity}

Direct and indirect studies of the activation (or deactivation) of CRF-positive neurons within the BNST have implicated a role for these cells in driving negative emotional behaviors and/or responding to stress-related or aversive stimuli (Pleil et al., 2015; Butler et al., 2016; Marcinkiewcz et al., 2016; Giardino et al., 2018; Lin et al., 2018; Fetterly et al., 2019). These findings suggest that greater activation of BNST-CRF neurons underlies aspects of the anxiety- and depressive-like behaviors observed in animal models of mood-related disorders. The GluN2D ${ }^{-1-}$ line presents similar phenotypes, and we found GluN2D-NMDARs to be functionally expressed on a large majority of BNST-CRF neurons. Further, we found excitatory drive onto these cells to be enhanced, whereas inhibitory drive was diminished in the GluN2D ${ }^{-1-}$, suggestive of a hyperactive state that has consistently been implicated in both clinical and preclinical literature with the pathology of multiple mood-related disorders (Arborelius et al., 1999; Keck and Holsboer, 2001; Bale and Vale, 2004; Ronan and Summers, 2011). Our in vivo recordings of the basal activity of these neurons in the GluN2D ${ }^{-/-}$demonstrated a robust increase in the frequency of calcium-mediated events, further supporting this conclusion and the possibility of the GluN2D-NMDARs emerging as a unique target for modulating the activity of the CRF system within the BNST.

\section{A region-specific role for BNST-GluN2D-NMDARs in regulating downstream behavior and cell type-specific physiology}

The downregulation and subsequent restricted expression of GluN2D known to occur during early development (Monyer et

\section{$\leftarrow$}

(red) in the dIBNST $\sim 4-5$ weeks after surgery. C, Left, Representative traces of isolated NMDAR-EPSCs recorded from GluN2D ${ }^{\text {fl/ffix }}$ BNST-CRF Cre/tdTomato-positive cells (Cre[ +$]$, red) and CRF tdTomato-positive, Cre-negative cells (Cre[-], black). Comparison of decay kinetics observed between $\mathrm{Cre}(-)$ and $\mathrm{Cre}(+)$ cells revealed a significant decrease in half tau (ms) measurements for $\mathrm{Cre}(+)$ cells compared with $\mathrm{Cre}(-)$, indicative of altered NMDAR function $(p=0.028)$. $\boldsymbol{D}$, Left, Representative traces of sEPSC recordings from $\mathrm{Cre}(-)$ and $\mathrm{Cre}(+)$ BNST-CRF cells. Summary data of comparisons of both frequency and amplitude metrics in Cre(-) and $\mathrm{Cre}(+)$ cells revealed a significant increase in sEPSC frequency in the $\mathrm{Cre}(+)$ group $(p=0.019)$. A trending, but nonsignificant, increase in $\mathrm{SEPSC}$ amplitude was also observed between groups $(p=0.053)$. Data are mean \pm SEM, with individual data points

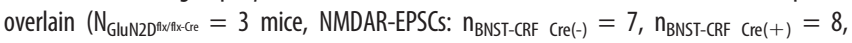
sEPSCS: $\left.n_{\text {BNST-CRF (re(-) }}=10, n_{\text {BNST-CRF Cre(+) }}=10\right) .{ }^{*} p \leq 0.05,{ }^{* *} p \leq 0.01$. al., 1994; Wenzel et al., 1996) suggest a complex role for GluN2D-NMDARs in the adult brain that may not be fully captured through the use of a constitutive KO. Thus, we developed and validated a GluN2D ${ }^{\mathrm{flx} / \mathrm{flx}}$ line to delete the subunit from the BNST of adult mice. BNST GluN2D deletion produced behavioral phenotypes also observed in the GluN2D ${ }^{-7-}$ (Yamamoto et al., 2017; Shelkar et al., 2019). Previous studies of NMDAR function in regions shown to contain synaptic or extrasynaptic GluN2D-NMDARs (subthalamic nucleus, hippocampus, and cerebellum) have shown the subunit to exert unique control over the deactivation time course of NMDAR-EPSCs (Swanger et al., 2015; von Engelhardt et al., 2015; Dubois et al., 2016), an effect we also show to be true at BNST-CRF cells in both the GluN2D ${ }^{-1-}$ and the GluN2 $\mathrm{D}^{\mathrm{flx} / \mathrm{flx}}$. The slower deactivation kinetics characteristic of GluN2D-NMDARs are thought to be imparted by the receptors' unique physiological properties (Monyer et al., 1994; Qian et al., 2005; Erreger et al., 2007), and may contribute to a greater temporal summation of excitatory signaling at cells containing these receptors (Bourne and Nicoll, 1993; Edmonds et al., 1995). Properties, such as these, have previously been shown to result in stronger and more robust plasticity (Carmignoto and Vicini, 1992; Malenka, 1994; Edmonds et al., 1995), and thus might explain the blunting in BNST STP we observe in the GluN2D ${ }^{-{ }_{-}}$.

GluN2D-NMDAR localization both presynaptically and postsynaptically has been speculated to allow these receptors to uniquely regulate glutamatergic signaling, with recent work in the cerebellum demonstrating that presynaptic GluN2D-NMDARs can act as detectors of glutamate spillover at the synapses of inhibitory interneurons to regulate GABA release and excitatory/ inhibitory transmission cross-talk (Dubois et al., 2016). GluN2DNMDARs have also been speculated to be extrasynaptically localized (Brickley et al., 2003; Harney et al., 2008; Costa et al., 2009), which may allow for these receptors to participate in the regulation of tonic glutamatergic currents at specific synapses (Papouin and Oliet, 2014). While similar extrasynaptic mechanisms may be in place at BNST-CRF cells, our data indicate the presence of synaptic GluN2D-NMDARs on these neurons via the changes in NMDAR-isolated EPSC amplitudes noted in GluN2D ${ }^{-1-}$ or DQP-1105-treated slices. The presence of both synaptic and extrasynaptic GluN2D-NMDARs has been supported by physiological studies of dopaminergic neurons in the substantia nigra (Morris et al., 2018), and suggests the idea of these receptors serving as both detectors of presynaptic glutamate release and ambient changes in extracellular glutamate levels to control excitatory input at the cell. It is important to note that we cannot rule out that regional deletion of GluN2D in the BNST also affects CRFnegative cells, and may result in potential changes in the surrounding BNST microcircuitry that could factor into the control of excitatory/inhibitory tone at BNST-CRF cells (Gracy and Pickel, 1995; Paquet and Smith, 2000; Turesson et al., 2013). Thus, further cell-specific manipulations of GluN2D-NMDAR function in the BNST are required to gain a more complete mechanistic understanding of its role in mediating regional excitatory signaling. Apart from extending these studies to the CRF-negative BNST cells that also express functional GluN2D-NMDARs, determining whether several of the key regions providing glutamatergic inputs to the BNST express the receptor (somatically, axonally, or dendritically) will also be essential to providing a more definitive understanding of GluN2D-mediated signaling in relation to stress-responsive or negative emotional behavior.

Together, our data show that GluN2D-NMDARs provide an important role in modulating excitatory activity both in key stress-responsive regions and cell populations implicated in 
mood- and anxiety-related disorders, and may position them as attractive targets for the development of novel therapeutics. These studies further establish a functionally relevant role for GluN2D-NMDARs in driving and shaping complex emotional behavior, and suggest an important need to develop a better understanding of these receptors' functional and modulatory roles in the neurocircuitry of emotional behavior. Considering the unique biophysical properties of GluN2D-NMDARs and their restricted expression in the adult brain, our findings here suggest that the manipulation of these receptors may avoid the undesirable side effects of current treatments aimed at both the glutamate and CRF signaling systems in affective disorders (Binneman et al., 2008; Preskorn et al., 2008; Coric et al., 2010; Iadarola et al., 2015; Weed et al., 2016; Pomrenze et al., 2017), and pave the way for further studies of novel targets informed at the level of region-, circuit-, and cell-centric physiology.

\section{References}

Acker TM, Yuan H, Hansen KB, Vance KM, Ogden KK, Jensen HS, Burger PB, Mullasseril P, Snyder JP, Liotta DC, Traynelis SF (2011) Mechanism for noncompetitive inhibition by novel GluN2C/D N-methyl-d-aspartate receptor subunit-selective modulators. Mol. Pharmacol 80:782-795.

Arborelius L, Owens MJ, Plotsky PM, Nemeroff CB (1999) The role of corticotropin-releasing factor in depression and anxiety disorders. J Endocrinol 160:1-12.

Bale TL, Vale WW (2004) CRF and CRF receptors: role in stress responsivity and other behaviors. Annu Rev Pharmacol Toxicol 44:525-557.

Balu DT, Coyle JT (2011) Glutamate receptor composition of the post-synaptic density is altered in genetic mouse models of NMDA receptor hypoand hyperfunction. Brain Res 1392:1-7.

Binneman B, Feltner D, Kolluri S, Shi Y, Qiu R, Stiger T (2008) A 6-week randomized, placebo-controlled trial of CP-316,311 (a selective CRH1 antagonist) in the treatment of major depression. Am J Psychiatry 165:617-620.

Bourne HR, Nicoll R (1993) Molecular machines integrate coincident synaptic signals. Cell 72:65-75.

Brickley SG, Misra C, Selina Mok MH, Mishina M, Cull-Candy SG (2003) NR2B and NR2D subunits coassemble in cerebellar Golgi cells to form a distinct NMDA receptor subtype restricted to extrasynaptic sites. J Neurosci 23:4958-4966.

Butler RK, Oliver EM, Sharko AC, Parilla-Carrero J, Kaigler KF, Fadel JR, Wilson MA (2016) Activation of corticotropin releasing factor-containing neurons in the rat central amygdala and bed nucleus of the stria terminalis following exposure to two different anxiogenic stressors. Behav Brain Res 304:92-101.

Carmignoto G, Vicini S (1992) Activity-dependent decrease in NMDA receptor responses during development of the visual-cortex. Science 258:10071011.

Centanni SW, Morris BD, Luchsinger JR, Bedse G, Fetterly TL, Patel S, Winder DG (2019) Endocannabinoid control of the insular-bed nucleus of the stria terminalis circuit regulates negative affective behavior associated with alcohol abstinence. Neuropsychopharmacology 44:526-537.

Chen Y, Molet J, Gunn BG, Ressler K, Baram TZ (2015) Diversity of reporter expression patterns in transgenic mouse lines targeting corticotropinreleasing hormone-expressing neurons. Endocrinology 156:4769-4780.

Ch'ng S, Fu J, Brown RM, McDougall SJ, Lawrence AJ (2018) The intersection of stress and reward: BNST modulation of aversive and appetitive states. Prog Neuropsychopharmacol Biol Psychiatry 87:108-125.

Conrad KL, Winder DG (2011) Altered anxiety-like behavior and long-term potentiation in the bed nucleus of the stria terminalis in adult mice exposed to chronic social isolation, unpredictable stress and ethanol beginning in adolescence. Alcohol 45:585-593.

Conrad KL, Louderback KM, Gessner CP, Winder DG (2011) Stress-induced alterations in anxiety-like behavior and adaptations in plasticity in the bed nucleus of the stria terminalis. Physiol Behav 104:248-256.

Coric V, Feldman HH, Oren DA, Shekhar A, Pultz J, Dockens RC, Wu X, Gentile KA, Huang SP, Emison E, Delmonte T, D'Souza BB, Zimbroff DL, Grebb JA, Goddard AW, Stock EG (2010) Multicenter, randomized, double-blind, active comparator and placebo-controlled trial of a corticotropin-releasing factor receptor-1 antagonist in generalized anxiety disorder. Depress Anxiety 27:417-425.

Costa BM, Feng B, Tsintsadze TS, Morley RM, Irvine MW, Tsintsadze V, Lozovaya NA, Jane DE, Monaghan DT (2009) N-methyl-D-aspartate (NMDA) receptor NR2 subunit selectivity of a series of novel piperazine2,3-dicarboxylate derivatives: preferential blockade of extrasynaptic NMDA receptors in the rat hippocampal CA3-CA1 synapse. J Pharmacol Exp Ther 331:618-626.

Crawley J, Goodwin FK (1980) Preliminary report of a simple animal behavior model for the anxiolytic effects of benzodiazepines. Pharmacol Biochem Behav 13:167-170.

Cull-Candy S, Brickley S, Farrant M (2001) NMDA receptor subunits: diversity, development and disease. Curr Opin Neurobiol 11:327-335.

Dong HW, Petrovich GD, Watts AG, Swanson LW (2001) Basic organization of projections from the oval and fusiform nuclei of the bed nuclei of the stria terminalis in adult rat brain. J Comp Neurol 436:430-455.

Dubois CJ, Lachamp PM, Sun L, Mishina M, Liu SJ (2016) Presynaptic GluN2D receptors detect glutamate spillover and regulate cerebellar GABA release. J Neurophysiol 115:271-285.

Dulawa SC, Hen R (2005) Recent advances in animal models of chronic antidepressant effects: the novelty-induced hypophagia test. Neurosci Biobehav Rev 29:771-783.

Edmonds B, Gibb AJ, Colquhoun D (1995) Mechanisms of activation of glutamate receptors and the time-course of excitatory synaptic currents. Annu Rev Physiol 57:495-519.

Erreger K, Geballe MT, Kristensen A, Chen PE, Hansen KB, Lee CJ, Yuan H, Le P, Lyuboslavsky PN, Micale N, Jørgensen L, Clausen RP, Wyllie DJ, Snyder JP, Traynelis SF (2007) Subunit-specific agonist activity at NR2A-, NR2B-, NR2C-, and NR2D-containing N-methyl-D-aspartate glutamate receptors. Mol Pharmacol 72:907-920.

Fetterly TL, Basu A, Nabit BP, Awad E, Williford KM, Centanni SW, Matthews RT, Silberman Y, Winder DG (2019) $\alpha 2$ A-adrenergic receptor activation decreases parabrachial nucleus excitatory drive onto BNST CRF neurons and reduces their activity in vivo. J Neurosci 39:472-484.

Ghamari-Langroudi M, Digby GJ, Sebag JA, Millhauser GL, Palomino R, Matthews R, Gillyard T, Panaro BL, Tough IR, Cox HM, Denton JS, Cone RD (2015) G-protein-independent coupling of MC4R to Kir7.1 in hypothalamic neurons. Nature 520:94-98.

Ghasemi M, Phillips C, Trillo L, De Miguel Z, Das D, Salehi A (2014) The role of NMDA receptors in the pathophysiology and treatment of mood disorders. Neurosci Biobehav Rev 47:336-358.

Giardino WJ, Eban-Rothschild A, Christoffel DJ, Li S, Malenka RC, de Lecea L (2018) Parallel circuits from the bed nucleus of the stria terminalis to the lateral hypothalamus drive opposing emotional states. Nat Neurosci 21:1084-1095.

Glangetas C, Massi L, Fois GR, Jalabert M, Girard D, Diana M, Yonehara K, Roska B, Xu C, Luthi A, Caille S, Georges F (2017) NMDA-receptor dependent plasticity in the bed nucleus of the stria terminalis triggers longterm anxiolysis. Nat Commun 8:14456.

Gracy KN, Pickel VM (1995) Comparative ultrastructural localization of the NMDAR1 glutamate receptor in the rat basolateral amygdala and bed nucleus of the stria terminalis. J Comp Neurol 362:71-85.

Graybeal C, Kiselycznyk C, Holmes A (2012) Stress-induced deficits in cognition and emotionality: a role for glutamate. Curr Top Behav Neurosci 12:189-207.

Hansen KB, Yi F, Perszyk RE, Furukawa H, Wollmuth LP, Gibb AJ, Traynelis SF (2018) Structure, function and allosteric modulation of NMDA receptors. J Gen Physiol 150:1081-1105.

Hanson E, Armbruster M, Lau LA, Sommer ME, Klaft Z, Swanger SA, Traynelis SF, Moss SJ, Noubary F, Chadchankar J, Dulla CG (2019) Tonic activation of GluN2C/GluN2D-containing NMDA receptors by ambient glutamate facilitates cortical interneuron maturation. J Neurosci 39:3611-3626.

Harney SC, Jane DE, Anwyl R (2008) Extrasynaptic NR2D-containing NMDARs are recruited to the synapse during LTP of NMDAR-EPSCs. J Neurosci 28:11685-11694.

Harris NA, Isaac AT, Gunther A, Merkel K, Melchior J, Xu M, Eguakun E, Perez R, Nabit BP, Flavin S, Gilsbach R, Shonesy B, Hein L, Abel T, Baumann A, Matthews R, Centanni SW, Winder DG (2018) Dorsal BNST $\alpha 2 \mathrm{~A}$-adrenergic receptors produce $\mathrm{HCN}$-dependent excitatory actions that initiate anxiogenic behaviors. J Neurosci 38:8922-8942. 
Holleran KM, Wilson HH, Fetterly TL, Bluett RJ, Centanni SW, Gilfarb RA, Rocco LE, Patel S, Winder DG (2016) Ketamine and MAG lipase inhibitor-dependent reversal of evolving depressive-like behavior during forced abstinence from alcohol drinking. Neuropsychopharmacology 41:20622071.

Iadarola ND, Niciu MJ, Richards EM, Vande Voort JL, Ballard ED, Lundin NB, Nugent AC, Machado-Vieira R, Zarate CA (2015) Ketamine and other N-methyl-D-aspartate receptor antagonists in the treatment of depression: a perspective review. Ther Adv Chronic Dis 6:97-114.

Ikeda K, Araki K, Takayama C, Inoue Y, Yagi T, Aizawa S, Mishina M (1995) Reduced spontaneous activity of mice defective in the $\varepsilon 4$ subunit of the NMDA receptor channel. Mol Brain Res 33:61-71.

Javitt DC, Schoepp D, Kalivas PW, Volkow ND, Zarate C, Merchant K, Bear MF, Umbricht D, Hajos M, Potter WZ, Lee C (2011) Translating glutamate: from pathophysiology to treatment. Sci Transl Med 3:102mr2.

Jennings JH, Sparta DR, Stamatakis AM, Ung RL, Pleil KE, Kash TL, Stuber GD (2013) Distinct extended amygdala circuits for divergent motivational states. Nature 496:224-228.

Kash TL, Pleil KE, Marcinkiewcz CA, Lowery-Gionta EG, Crowley N, Mazzone C, Sugam J, Hardaway JA, McElligott ZA (2015) Neuropeptide regulation of signaling and behavior in the BNST. Mol Cells 38:1-13.

Keck ME, Holsboer F (2001) Hyperactivity of CRH neuronal circuits as a target for therapeutic interventions in affective disorders. Peptides 22:835844.

Kim SY, Adhikari A, Lee SY, Marshel JH, Kim CK, Mallory CS, Lo M, Pak S, Mattis J, Lim BK, Malenka RC, Warden MR, Neve R, Tye KM, Deisseroth K (2013) Diverging neural pathways assemble a behavioral state from separable features in anxiety. Nature 496:219-233.

Lebow M, Neufeld-Cohen A, Kuperman Y, Tsoory M, Gil S, Chen A (2012) Susceptibility to PTSD-like behavior is mediated by corticotropin-releasing factor receptor type 2 levels in the bed nucleus of the stria terminalis. J Neurosci 32:6906-6916.

Lebow MA, Chen A (2016) Overshadowed by the amygdala: the bed nucleus of the stria terminalis emerges as key to psychiatric disorders. Mol Psychiatry 21:450-463.

Lin X, Itoga CA, Taha S, Li MH, Chen R, Sami K, Berton F, Francesconi W, $\mathrm{Xu} \mathrm{X}$ (2018) c-fos mapping of brain regions activated by multi-modal and electric foot shock stress. Neurobiol Stress 8:92-102.

Louderback KM, Wills TA, Muglia LJ, Winder DG (2013) Knockdown of BNST GluN2B-containing NMDA receptors mimics the actions of ketamine on novelty-induced hypophagia. Transl Psychiatry 3:e331.

Malenka RC (1994) Synaptic plasticity in the hippocampus: LTP and LTD. Cell 78:535-538.

Marcinkiewcz CA, Mazzone CM, D’Agostino G, Halladay LR, Hardaway JA, DiBerto JF, Navarro M, Burnham N, Cristiano C, Dorrier CE, Tipton GJ, Ramakrishnan C, Kozicz T, Deisseroth K, Thiele TE, McElligott ZA, Holmes A, Heisler LK, Kash TL (2016) Serotonin engages an anxiety and fear-promoting circuit in the extended amygdala. Nature 537:97-101.

McElligott ZA, Winder DG (2009) Modulation of glutamatergic synaptic transmission in the bed nucleus of the stria terminalis. Prog Neuropsychopharmacol Biol Psychiatry 33:1329-1335.

Miyamoto Y, Yamada K, Noda Y, Mori H, Mishina M, Nabeshima T (2002) Lower sensitivity to stress and altered monoaminergic neuronal function in mice lacking the NMDA receptor epsilon 4 subunit. J Neurosci 22:2335-2342.

Monyer H, Burnashev N, Laurie DJ, Sakmann B, Seeburg PH (1994) Developmental and regional expression in the rat brain and functional properties of four NMDA receptors. Neuron 12:529-540.

Morris PG, Mishina M, Jones S (2018) Altered synaptic and extrasynaptic NMDA receptor properties in substantia nigra dopaminergic neurons from mice lacking the GluN2D subunit. Front Cell Neurosci 12:354

Obiang P, Macrez R, Jullienne A, Bertrand T, Lesept F, Ali C, Maubert E, Vivien D, Agin V (2012) GluN2D subunit-containing NMDA receptors control tissue plasminogen activator-mediated spatial memory. J. Neurosci 32:12776-12734.

Olsen CM, Winder DG (2010) Operant sensation seeking in the mouse. J Vis $\operatorname{Exp} 45$ :

Paoletti P, Bellone C, Zhou Q (2013) NMDA receptor subunit diversity: impact on receptor properties, synaptic plasticity and disease. Nat Rev Neurosci 14:383-400.
Papouin T, Oliet SH (2014) Organization, control and function of extrasynaptic NMDA receptors. Philos Trans $\mathrm{R}$ Soc Lond B Biol Sci 369:20130601.

Paquet M, Smith Y (2000) Presynaptic NMDA receptor subunit immunoreactivity in GABAergic terminals in rat brain. J Comp Neurol 423:330347.

Paxinos G, Franklin B (2004) The mouse brain in stereotaxic coordinates, Ed 3. San Diego: Academic.

Pleil KE, Rinker JA, Lowery-Gionta EG, Mazzone CM, McCall NM, Kendra AM, Olson DP, Lowell BB, Grant KA, Thiele TE, Kash TL (2015) NPY signaling inhibits extended amygdala CRF neurons to suppress binge alcohol drinking. Nat Neurosci 18:545-552.

Pomrenze MB, Fetterly TL, Winder DG, Messing RO (2017) The corticotropin releasing factor receptor 1 in alcohol use disorder: still a valid drug target? Alcohol Clin Exp Res 41:1986-1999.

Preskorn SH, Baker B, Kolluri S, Menniti FS, Krams M, Landen JW (2008) An innovative design to establish proof of concept of the antidepressant effects of the NR2B subunit selective N-methyl-D-aspartate antagonist, CP-101,606, in patients with treatment-refractory major depressive disorder. J Clin Psychopharmacol 28:631-637.

Qian A, Buller AL, Johnson JW (2005) NR2 subunit dependence of NMDA receptor channel block by external $\mathrm{Mg}^{2+}$. J Physiol 562:319-331.

Ronan PJ, Summers CH (2011) Molecular signaling and translational significance of the corticotropin releasing factor system. In: The brain as a drug target: progress in molecular biology and translational science (Rahman S, ed), pp 235-292. San Diego: Academic.

Sanacora G, Treccani G, Popoli M (2012) Towards a glutamate hypothesis of depression: an emerging frontier of neuropsychopharmacology for mood disorders. Neuropharmacology 62:63-77.

Sanacora G, Zarate CA, Krystal JH, Manji HK (2008) Targeting the glutamatergic system to develop novel, improved therapeutics for mood disorders. Nat Rev Drug Discov 7:426-437.

Shelkar GP, Pavuluri R, Gandhi PJ, Ravikrishnan A, Gawande DY, Liu J, Stairs DJ, Ugale RR, Dravid SM (2019) Differential effect of NMDA receptor GluN2C and GluN2D subunit ablation on behavior and channel blocker-induced schizophrenia phenotypes. Sci Rep 9:7572.

Sheng M, Cummings J, Roldan LA, Jan YN, Jan LY (1994) Changing subunit composition of heteromeric NMDA receptors during development of rat cortex. Nature 368:144-147.

Silberman Y, Winder DG (2013) Emerging role for corticotropin releasing factor signaling in the bed nucleus of the stria terminalis at the intersection of stress and reward. Front Psychiatry 4:42.

Silberman Y, Matthews RT, Winder DG (2013) A corticotropin releasing factor pathway for ethanol regulation of the ventral tegmental area in the bed nucleus of the stria terminalis. J Neurosci 33:950-966.

Sink KS, Walker DL, Freeman SM, Flandreau EI, Ressler KJ, Davis M (2013) Effects of continuously enhanced corticotropin releasing factor expression within the bed nucleus of the stria terminalis on conditioned and unconditioned anxiety. Mol Psychiatry 18:308-319.

Swanger SA, Vance KM, Pare JF, Sotty F, Fog K, Smith Y, Traynelis SF (2015) NMDA receptors containing the GluN2D subunit control neuronal function in the subthalamic nucleus. J Neurosci 35:1597115983.

Turesson HK, Rodriguez-Sierra OE, Pare D (2013) Intrinsic connections in the anterior part of the bed nucleus of the stria terminalis. J Neurophysiol 109:2438-2450.

Vicini S, Wang JF, Li JH, Zhu WJ, Wang YH, Luo JH, Wolfe BB, Grayson DR (1998) Functional and pharmacological differences between recombinant N-methyl-D-aspartate receptors. J Neurophysiol 79:555566.

Volianskis A, Bannister N, Collett VJ, Irvine MW, Monaghan DT, Fitzjohn SM, Jensen MS, Jane DE, Collingridge GL (2013) Different NMDA receptor subtypes mediate induction of long-term potentiation and two forms of short-term potentiation at CA1 synapses in rat hippocampus in vitro. J Physiol 591:955-972.

Volianskis A, France G, Jensen MS, Bortolotto ZA, Jane DE, Collingridge GL (2015) Long-term potentiation and the role of N-methyl-D-aspartate receptors. Brain Res 1621:5-16.

von Engelhardt J, Bocklisch C, Tonges L, Herb A, Mishina M, Monyer H (2015) GluN2D-containing NMDA receptors-mediate synaptic currents in hippocampal interneurons and pyramidal cells in juvenile mice. Front Cell Neurosci 9:95. 
Watanabe M, Inoue Y, Sakimura K, Mishina M (1992) Developmental changes in distribution of NMDA receptor channel subunit mRNAs. Dev Neurosci 3:1138-1140.

Watanabe M, Inou Y, Sakimura K, Mishina M (1993) Distinct spatio-temporal distributions of the NMDA receptor channel subunit mRNAs in the brain. Ann NY Acad Sci 707:463-466.

Weed MR, Bookbinder M, Polino J, Keavy D, Cardinal RN, SimmermacherMayer J, Cometa FL, King D, Thangathirupathy S, Macor JE, Bristow LJ (2016) Negative allosteric modulators selective for the NR2B subtype of the NMDA receptor impair cognition in multiple domains. Neuropsychopharmacology 41:568-577.

Wenzel A, Villa M, Mohler H, Benke D (1996) Developmental and regional expression of NMDA receptor subtypes containing the NR2D subunit in rat brain. J Neurochem 66:1240-1248.

Wills TA, Klug JR, Silberman Y, Baucum AJ, Weitlauf C, Colbran RJ, Delpire E, Winder DG (2012) GluN2B subunit deletion reveals key role in acute and chronic ethanol sensitivity of glutamate synapses in bed nucleus of the stria terminalis. Proc Natl Acad Sci USA 109: E278-E287.

Yamamoto H, Kamegaya E, Hagino Y, Takamatsu Y, Sawada W, Matsuzawa M, Ide S, Yamamoto T, Mishina M, Ikeda K (2017) Loss of GluN2D subunit results in social recognition deficit, social stress, 5$\mathrm{HT} 2 \mathrm{C}$ receptor dysfunction, and anhedonia in mice. Neuropharmacology 112:188-197.

Yamasaki M, Okada R, Takasaki C, Toki S, Fukaya M, Natsume R, Sakimura K, Mishina M, Shirakawa T, Watanabe M (2014) Opposing role of NMDA receptor GluN2B and GluN2D in somatosensory development and maturation. J Neurosci 34:11534-11548.

Zhang X, Feng ZJ, Chergui K (2014) GluN2D-containing NMDA receptors inhibit neurotransmission in the mouse striatum through a cholinergic mechanism: implication for Parkinson's disease. J Neurochem 129:581590. 